\title{
Intertemporal Tradeoffs for Gains and Losses: An Experimental Measurement of Discounted Utility ${ }^{*}$
}

\author{
Mohammed Abdellaoui ${ }^{\mathrm{a}}$, Arthur E. Attema ${ }^{\mathrm{b}}$, and Han Bleichrodt ${ }^{\mathrm{b}, \mathrm{f}}$ \\ ${ }^{a}$ CNRS, GRID, Maison de la Recherche de l'ESTP, 30 Avenue du Président Wilson, 94230 Cachan, \\ France.(abdellaoui@grid.ensam.estp.fr) \\ ${ }^{b}$ Dept. of Economics, H13-27, Erasmus University, P.O. Box 1738, 3000 DR Rotterdam, The \\ Netherlands.(attema@few.eur.nl,bleichrodt@few.eur.nl)
}

September 2006

* We are grateful to Peter P. Wakker for his thorough comments on previous drafts. We also thank Kirsten I.M. Rohde for useful suggestions. Arthur Attema's and Han Bleichrodt's research was made possible through a VIDI-grant from the Netherlands Organization for Scientific Research (NWO).

${ }^{\ddagger}$ Corresponding author. 


\begin{abstract}
This paper is the first to measure utility in intertemporal choice and presents new and more robust evidence on the discounting of money outcomes. Our measurement method is parameterfree in the sense that it requires no assumptions about utility or discounting. We found that intertemporal utility was concave for gains and convex for losses, consistent with a hypothesis put forward by Loewenstein and Prelec (1992). Utility in intertemporal choice was close to utility in decision under risk and uncertainty, suggesting that there may be one unifying concept of utility that applies to all of economics. The existence of one concept of utility is important for applied economics, because it largely reduces data requirements. Discount rates declined over time, but less so than has been observed in previous studies that assumed linear utility. Of the main discounted utility models, Loewenstein and Prelec's (1992) generalized hyperbolic discounting model best fitted our data. The widely-used quasi-hyperbolic model fitted the data only slightly better than constant discounting. Finally, we obtained evidence of an asymmetry in discounting between gains and losses, which, in contrast with earlier findings, cannot be explained by a framing effect.
\end{abstract}

Key Words: Intertemporal Choice, Utility Measurement, Foundations of Utility, Hyperbolic Discounting, Gain-Loss Asymmetry. 


\section{Introduction}

Many economic decisions involve outcomes that occur at different points in time. To model such decisions, discounted utility models are typically used. These models combine a utility function that reflects attitudes towards outcomes and a discount function that captures the effect of the passage of time. The most widely used discounted utility model in economics is constant discounting in which the discount function is determined by a constant rate of discount. Empirical studies on time preference have observed that discount rates are not constant but decrease over time, a phenomenon referred to as decreasing impatience (Frederick et al. 2002, Read 2004). These findings have led to the development of alternative discounted utility models, commonly referred to as hyperbolic discounting. The hyperbolic discounting models are consistent with decreasing impatience and have become quickly popular in economics. Today many applications are based on hyperbolic discounting, in particular on quasi-hyperbolic discounting a model that was first proposed by Phelps and Polak (1968) and made popular by Laibson (1997).

Empirical measurement of discounted utility models is complex, because it requires the simultaneous elicitation of the utility function and the discount function. Previous studies have side-stepped this problem and have assumed specific functional forms for the utility function and the discount function. In particular, most studies have assumed linear utility. A drawback of making parametric assumptions is that the quality of the estimation comes to depend on the choice of functional forms. For example, if utility is concave instead of linear then falsely

\footnotetext{
${ }^{1}$ Examples of applications based on quasi-hyperbolic discounting include Laibson (1997), Bernheim et al. (2001), Harris and Laibson (2001), Krusell and Smith (2003), and Salanié and Treich (2006) for saving, O'Donoghue and Rabin (1999) and Brocas and Carrillo (2001) for procrastination, Brocas and Carrillo (2000) for the value of information, Gruber and Köszegi (2001) for addiction, Bénabou and Tirole (2002) for self-confidence, Diamond and Köszegi (2003) for retirement, and Karp (2005) for global warming.
} 
assuming linear utility will lead to an overestimation of discount rates. It should be noted that most empirical studies have indeed found high discount rates. Another limitation of assuming functional forms for utility is that no or only limited information is obtained on the intertemporal utility function. Consequently, in spite of the importance of intertemporal preferences and discounted utility models in economics, there exists to date no study that has actually measured the utility function in intertemporal choice.

In light of the above problems, this paper presents a new method to measure both intertemporal utility and the discount function without making any assumptions about functional forms. It is in this sense that we refer to our method as parameter-free. An additional advantage of our method is that it allows measuring utility and discounting at the individual level and, therefore, takes account of heterogeneity in individual preferences. We applied out method in an experimental study and, hence, this paper is the first to measure intertemporal utility and to obtain robust estimates of the discount function and at the individual level.

Our data allowed us to address several empirical questions. First, we obtained evidence on the shape of the utility function in intertemporal choice. Classical economics assumes that this utility function is everywhere concave. Loewenstein and Prelec (1992), by contrast, posit that people treat gains and losses differently and have concave utility for gains and convex utility for losses. We performed our experiment both for gains and for losses, which made it possible to compare the predictions of classical economics with Loewenstein and Prelec's (1992) hypotheses.

Second, our findings on intertemporal utility allowed us to shed some empirical light on a long-standing issue in economics, whether there exists one unifying concept of utility that applies to all of economics or whether different concepts of utility apply in different decision 
contexts (for a history see Wakker 1994). No empirical guidance exists on this debate, because few measurements of utility were available in decision contexts other than decision under risk. The existence of one unifying concept of utility would be highly desirable for applied economics because it implies that utility measurements can be transferred across decision contexts thereby greatly reducing data requirements. By comparing our utility measurements with those from the literature on decision under risk, we were able to provide insights regarding the existence of one unifying concept of utility.

Third, we could test whether the commonly observed pattern of declining discount rates persisted when the assumption of linear utility was relaxed. As argued above, there are grounds to suspect that previous observations of decreasing impatience may, at least partly, have been caused by falsely assuming linear utility. Our data also made it possible to compare the fit of constant discounting with that of its main hyperbolic alternative, quasi-hyperbolic discounting, and three other popular hyperbolic discounting models. Many studies have provided support for hyperbolic discounting (e.g. Ainslie 1975, Thaler 1981, Benzion et al. 1989, Kirby and Marakovic 1995), ${ }^{2}$ but little insight exists into which hyperbolic model most accurately describes intertemporal preferences. The popularity of quasi-hyperbolic discounting relative to other hyperbolic discounting models in economics is based on its theoretical tractability and not on its displayed descriptive superiority.

Finally, we could perform a robust test for an asymmetry between the discounting of gains and losses that has been observed in some earlier studies (Thaler 1981, Benzion et al. 1989). One explanation for the gain-loss asymmetry may be that it is an artifact of the assumption of linear utility. When utility is concave for gains, leading to an overestimation of

\footnotetext{
${ }^{2}$ For findings challenging hyperbolic discounting see Read (2001) and Read et al. (2005).
} 
discount rates for gains, and closer to linear for losses, leading to less distortion of discount rates for losses, then the gain-loss asymmetry will follow from the assumption of linear utility even when people have the same discount function for gains and for losses. The pattern "concave utility for gains and more linear utility for losses" has been observed in several empirical studies on decision under risk (Fishburn and Kochenberger 1979, Abdellaoui 2000, Pennings and Smidts 2003).

In what follows, Section 2 reviews previous theoretical and empirical research on intertemporal choice. Section 3 presents our method for measuring discounted utility. The design and results of our experiment are specified in Sections 4 and 5 and are discussed in Section 6. We conclude in Section 7.

\section{Theory and Existing Empirical Evidence}

We consider temporal profiles $\left(\mathrm{x}_{0}, \ldots, \mathrm{x}_{\mathrm{T}}\right)$, where $\mathrm{x}_{\mathrm{t}}$ denotes outcome $\mathrm{x}$ at time point $\mathrm{t}$ and time point 0 is the present. Outcomes can be money amounts but also binary prospects (p:M; m) denoting money amount $\mathrm{M}$ with probability $\mathrm{p}$ and money amount $\mathrm{m}$ with probability $1-\mathrm{p}$. Throughout we assume that 0 , i.e. receiving nothing, belongs to the set of outcomes.

We examine preferences $\succcurlyeq$ over temporal profiles. The relations $\leqslant, \prec,>$, and $\sim$ are as usual. Preferences over outcomes are derived from preferences over constant temporal profiles, where $x_{1}=\ldots=x_{T}=x$. We say that $\alpha \geqslant \beta$ if and only if $(\alpha, \ldots, \alpha) \geqslant(\beta, \ldots, \beta)$, i.e. receiving $\alpha$ at all points in time is preferred to receiving $\beta$ at all points in time.

We assume that the decision maker perceives outcomes relative to 0. Gains are outcomes preferred to 0 and losses are outcomes less preferred than 0 . We will only consider temporal prospects where all outcomes have the same sign, i.e. either all outcomes are gains or all 
outcomes are losses. A function $\mathrm{V}$ represents $\geqslant$ when for all $\mathrm{x}, \mathrm{y}, \mathrm{x} \geqslant \mathrm{y}$ if and only if $\mathrm{V}(\mathrm{x}) \geq$ $\mathrm{V}(\mathrm{y})$. Throughout, we will assume that preferences over temporal profiles can be represented by the general discounting model

$$
\mathrm{V}\left(\mathrm{x}_{0}, \ldots, \mathrm{x}_{\mathrm{T}}\right)=\sum_{\mathrm{t}=0}^{\mathrm{T}} \lambda_{\mathrm{t}}^{\mathrm{i}} \mathrm{u}\left(\mathrm{x}_{\mathrm{t}}\right), \mathrm{i}=+,-
$$

with the time weights $\lambda_{\mathrm{t}}^{\mathrm{i}}$ positive and $\lambda_{0}^{\mathrm{i}}=1$ and $\mathrm{u}$ a real-valued utility function that represents preferences over outcomes. We allow that the time weights differ for gains and for losses. To keep the notation tractable, we will suppress the sign-dependence of the $\lambda_{t}^{i}$ and simply write $\lambda_{t}$ in what follows. Whether the time weights for gains or the time weights for losses apply will be apparent from the decision context.

The time weights $\lambda_{t}$ are unique and the utility function is unique up to unit. Equation (1) is general in the sense that it presumes nothing about the ordering or the relative magnitude of the $\lambda_{t}$. The main models of discounting are all special cases of (1). A preference foundation for general discounting has been given by Krantz et al. (1971, Theorem 6.15).

The best-known special case of (1) is constant discounting, which was introduced by Samuelson (1937) and which is still the most widely used discounted utility model in economics. Constant discounting entails that the time weights $\lambda_{t}$ in (1) are equal to $\frac{1}{(1+\delta)^{t}}$, where $\delta$ is the constant discount rate. As mentioned before, experimental evidence has cast doubts on the descriptive validity of the constant discounting. In this paper we focus on two violations of constant discounting: decreasing impatience, the finding that discount rates are not constant but 
decrease over time, and the gain-loss asymmetry, the finding that people discount gains and losses differently. ${ }^{3}$

Many studies have observed decreasing impatience. See for example Thaler (1981), Benzion et al. (1989), Shelley (1993), and Kirby and Marakovic (1995) for money amounts and Chapman (1996), Lazaro et al. (2001), and van der Pol and Cairns (2002) for health. An exception is Ahlbrecht and Weber (1997), who only observed decreasing impatience in a matching task, but not in a choice task. The common assumption in these studies was linear intertemporal utility. Chapman (1996) also considered power utility. She elicited utility in an atemporal setting using introspective strength of preference judgements and then assumed that this function could also be applied to intertemporal choice. ${ }^{4}$ Whether utility is transferable across decision domains is highly controversial in economics. Arrow (1951), Savage (1954), Luce and Raiffa (1957), and Fishburn (1989) amongst others have argued against such transferability.

There is some controversy in the literature as to whether decreasing impatience holds in general or whether violations of constant discounting occur only in the first time interval. The latter hypothesis is referred to as the immediacy effect and underlies quasi-hyperbolic discounting, which will be discussed below. Some studies found support for the immediacy effect (Bleichrodt and Johannesson 2001, Frederick et al. 2002); others rejected it and also found violations of constant discounting for later time intervals (Kirby and Herrnstein 1995, Kirby 1997, Lazaro et al. 2001).

The gain-loss asymmetry is empirically less well-established than decreasing impatience. Thaler (1981) and Benzion et al. (1989) found evidence of the gain-loss asymmetry, but Shelley

\footnotetext{
${ }^{3}$ The gain-loss asymmetry can be accommodated within the general discounting model because we allow that the $\lambda_{t}$ differ between gains and losses.
} 
(1993) showed that their findings could be explained by a framing effect. In a neutral frame, she found no evidence of a gain-loss asymmetry, a finding that was later confirmed by Ahlbrecht and Weber (1997).

\subsection{Alternative discounting models}

Several alternative discounting models have been proposed in response to the observed violations of constant discounting. These models were primarily designed to explain decreasing impatience. Except for the model of Loewenstein and Prelec (1992), they make no distinction between gains and losses and, hence, cannot explain the gain-loss asymmetry.

Loewenstein and Prelec (1992) suggested to use a generalized hyperbolic discounting model, in which $\lambda_{t}=\frac{1}{(1+\gamma t)^{\alpha / \gamma}}$, with $\alpha, \gamma>0$. The parameter $\gamma$ determines the departure from constant discounting. The limiting case of $\gamma$ tending to zero yields constant discounting. Because $\alpha$ is positive, the discount rates implied by generalized hyperbolic discounting decrease over time, corresponding to decreasing impatience. Loewenstein and Prelec assumed that the time weights were the same for gains and for losses. To explain the gain-loss asymmetry, they suggested that the intertemporal utility function $u$ in (1) is concave for gains and convex for losses and is more elastic for losses than for gains. The special case of generalized hyperbolic discounting in which $\alpha=\gamma$ was initially proposed by Herrnstein (1981) and is referred to as proportional or hyperbolic discounting. Power discounting (Harvey 1986), is the special case of generalized hyperbolic discounting in which $\gamma=1$.

\footnotetext{
${ }^{4}$ In a recent working paper Andersen et al. (2006) used a comparable strategy: they estimated power utility from decision under risk and then applied this function to intertemporal choice.
} 
Quasi-hyperbolic discounting (Phelps and Pollak 1968, Laibson 1997), is the special case

of (1) where $\lambda_{t}=\frac{\beta}{(1+\delta)^{t}}$ for $t>0$ with $0<\beta \leq 1$. The only difference with constant discounting is the parameter $\beta$. Constant discounting is the special case of quasi-hyperbolic discounting with $\beta$ $=1$. If $\beta<1$ then the outcome in the first period is discounted at a higher rate than the discount rate that is used to compare the outcomes in any two other contiguous future periods. In other words, $\beta<1$ models the immediacy effect.

\section{Measurement Method}

Our method to measure the general discounting model (1) consisted of two stages. In the first stage, choices between temporal profiles were constructed in such a manner that the time weights $\lambda_{t}$ canceled, allowing us to measure utility without the need to know the time weights. This way of measuring utilities resembles the utility measurement method of Wakker and Deneffe (1996) for decision under uncertainty. The difficulty in translating their method to intertemporal choice is that the utility function in intertemporal choice has different uniqueness properties than the utility function in decision under uncertainty. In the second stage, we used the elicited utilities to measure the time weights. Hence, we could measure the time weights from the elicited utilities and no assumptions about the shape of utility had to be made.

Our method involves choosing the utility of two outcomes and, as is shown in Appendix A, this is only allowed when all temporal profiles involve the same unit of time and have common final periods. That is, for all profiles $\left(\mathrm{x}_{1}, \ldots, \mathrm{x}_{\mathrm{T}}\right)$ and $\left(\mathrm{y}_{1}, \ldots, \mathrm{y}_{\mathrm{S}}\right)$, the difference in timing between $x_{t-1}$ and $x_{t}$ is equal to the difference in timing between $y_{t-1}$ and $y_{t}$ and $T=S$. Hence, we 
will assume such profiles in the remainder of this Section and we only used such profiles in our experimental study described in Section 4.

\section{First stage: measurement of utility}

Let $\mathrm{x}_{0} \mathrm{y}_{\mathrm{t}}$ denote the temporal profile that gives $\mathrm{x}$ now, $\mathrm{y}$ at time point $\mathrm{t}$ and nothing in all other periods. The first step in the measurement of utility was to select two gauge outcomes $\mathrm{G}$ and $\mathrm{g}$ and a starting outcome $\mathrm{x}^{0}$. Superscripts serve to distinguish outcomes and do not denote powers. We then elicited the outcome $x^{1}$ such that a participant was indifferent between $g_{0} x_{t}^{1}$ and $\mathrm{G}_{0} \mathrm{x}_{\mathrm{t}}^{0}$. In terms of the general discounting model (1) this indifference implies that

$$
u(g)+\lambda_{t} u\left(x^{1}\right)+\sum_{s \neq 0, t} \lambda_{s} u(0)=u(G)+\lambda_{t} u\left(x^{0}\right)+\sum_{s \neq 0, t} \lambda_{s} u(0)
$$

and, hence,

$$
\mathrm{u}\left(\mathrm{x}^{1}\right)-\mathrm{u}\left(\mathrm{x}^{0}\right)=\frac{\mathrm{u}(\mathrm{G})-\mathrm{u}(\mathrm{g})}{\lambda_{\mathrm{t}}}
$$

The outcome $\mathrm{x}^{1}$ was used as an input in the next question where we elicited $\mathrm{x}^{2}$ such that indifference held between $\mathrm{g}_{0} \mathrm{x}_{\mathrm{t}}^{2}$ and $\mathrm{G}_{0} \mathrm{x}_{\mathrm{t}}^{1}$. By (1) and a similar argument as above, this indifference implied that

$$
u\left(x^{2}\right)-u\left(x^{1}\right)=\frac{u(G)-u(g)}{\lambda_{t}}
$$

Thus, $u\left(x^{2}\right)-u\left(x^{1}\right)=u\left(x^{1}\right)-u\left(x^{0}\right)$. We proceeded to elicit indifferences $g_{0} x_{t}^{j} \sim G_{0} x_{t}^{j-1}, j=$ $3, \ldots, \mathrm{k}$, and obtained a standard sequence of outcomes $\mathrm{x}^{0}, \mathrm{x}^{1}, \ldots, \mathrm{x}^{\mathrm{k}}$ such that successive 
elements of the sequence were equally spaced in terms of utility: $u\left(x^{j+1}\right)-u\left(x^{j}\right)=u\left(x^{1}\right)-u\left(x^{0}\right)$ for $\mathrm{j}=2, \ldots, \mathrm{k}-1$. It is easily verified that if $\mathrm{G}>\mathrm{g}$ then the standard sequence is increasing, i.e. $\mathrm{x}^{\mathrm{j}}$ $>\mathrm{x}^{\mathrm{j}-1}$ for $\mathrm{j}=1, \ldots, \mathrm{k}$. If $\mathrm{G} \prec \mathrm{g}$ then the standard sequence is decreasing, i.e. $\mathrm{x}^{\mathrm{j}} \prec \mathrm{x}^{\mathrm{j}-1}$ for $\mathrm{j}=$ $1, \ldots, \mathrm{k}$.

Appendix A shows that if all temporal profiles involve the same unit of time and have common final periods then we can freely choose the utility of two outcomes. Since we only considered such temporal profiles, we set $\mathrm{u}\left(\mathrm{x}^{\mathrm{k}}\right)=1$ and $\mathrm{u}\left(\mathrm{x}^{0}\right)=0$ for increasing standard sequences, yielding $\mathrm{u}\left(\mathrm{x}^{\mathrm{j}}\right)=\mathrm{j} / \mathrm{k}$ for $\mathrm{j}=0, \ldots, \mathrm{k}$. For decreasing standard sequences, we set $\mathrm{u}\left(\mathrm{x}^{\mathrm{k}}\right)=$ -1 and $\mathrm{u}\left(\mathrm{x}^{0}\right)=0$, yielding $\mathrm{u}\left(\mathrm{x}^{\mathrm{j}}\right)=-\mathrm{j} / \mathrm{k}$ for $\mathrm{j}=0, \ldots, \mathrm{k}$.

\section{Second stage: measurement of the time weights}

Once the utility function is known, the measurement of the time weights is straightforward. We elicited the outcome $\mathrm{z}$ such that a participant was indifferent between $\mathrm{z}_{0} \mathrm{x}_{\mathrm{t}}^{0}$, i.e. $z$ now and $x^{0}$ at time point $t$, and $x_{0}^{0} x_{t}{ }_{t}$, i.e. $x^{0}$ now and $x^{k}$ at time point $t$. By (1) we obtain that

$$
u(z)+\lambda_{t} u\left(x^{0}\right)+\sum_{s \neq 0, t} \lambda_{s} u(0)=u\left(x^{0}\right)+\lambda_{t} u\left(x^{k}\right)+\sum_{s \neq 0, t} \lambda_{s} u(0)
$$

and, hence, by the adopted scaling, $|\mathrm{u}(\mathrm{z})|=\lambda_{\mathrm{t}}$. By varying $\mathrm{t}$, we could elicit different time weights. The elicited outcomes z typically did not belong to the standard sequence elicited in the first stage and their utility was unknown. If participants have positive time preference, however, then $\mathrm{z}$ will lie between two elements of the elicited standard sequence and we could approximate the utility of $\mathrm{z}$ through the known utility of these elements of the standard sequence. This 
approximation will be good if successive elements of the standard sequence are not too far apart. We return to the issue of approximation below.

\section{Experiment}

The aim of the experiment was to elicit the intertemporal utility function and the time weights both for gains and for losses through the procedure outlined above.

\section{Participants and incentives}

Seventy participants were recruited and were paid a fixed amount of $€ 12.50$ to join the experiment. The participants were students from different faculties of the Erasmus University Rotterdam. Before the actual experiment, we tested the design in several pilot sessions using other students and university staff as participants.

Throughout the experiment we used hypothetical choices. There were several reasons for using hypothetical instead of real incentives. A first reason was the problem in organizing payments in the future, some of which occurred in four years time. Second, because utility tends to be close to linear for small amounts (Wakker and Deneffe 1996), we used large money amounts to capture the effect of utility curvature. Paying these amounts for real would have been prohibitively expensive. Third, there were ethical constraints to use real incentives for the losses part of the experiment. Finally, in hypothetical questions one can ask participants to assume that there is no risk associated with future payments. With real stakes, participants may consider the receipt of future money amounts uncertain, which could inflate the discounting of these amounts.

Some studies have investigated the differences between real and hypothetical money amounts in intertemporal decision making, but no clear evidence exists that hypothetical 
amounts are discounted differently than real amounts (Frederick et al. 2002). In decision under uncertainty, real and hypothetical incentives do not seem to give qualitatively different results, although real incentives tend to reduce data variability (Camerer and Hogarth 1999, Hertwig and Ortmann 2001).

\section{Procedure}

The experiment was executed with each participant individually using a computer program. Answers were entered into the computer by the interviewer, so that participants could concentrate on the questions and mistakes could be reduced. Each individual session lasted between 30 and 45 minutes. Throughout the experiment, participants were encouraged to think aloud to obtain insight into the reasoning underlying their answers.

All indifferences were elicited through a sequence of choices. We used choices because empirical evidence suggests that choice-indifferences lead to fewer inconsistencies than indifferences determined by matching, where participants are directly asked to state their indifference value (Bostic et al. 1990). Because we used choices, our study employs what Shelley (1993) refers to as a neutral frame and, hence, we could test whether the gain-loss asymmetry was due to a framing effect.

The interviewer used a scroll bar to vary the value of the outcome that we sought to elicit, starting with values for which preferences were clear and then "zooming in" on the indifference value. Examples of the computer screens that participants faced in the first and the second stage of the experiment are in the Appendix.

We elicited the general discounted utility model first for gains and then for losses. We always started with the gains part because we learnt from the pilot sessions that this made it 
easier for participants to understand the choice task. Both parts were preceded by a practice question. Recall from Section 3 that our method involved the selection of two gauge outcomes denoted $\mathrm{G}$ and $\mathrm{g}$. For gains (losses), $\mathrm{G}$ was a prospect giving a 50\% chance of winning (losing) $€ 2000$ (and nothing otherwise) and g was a prospect giving a 50\% chance of winning (losing) $€ 500$. Hence, we elicited increasing standard sequences for gains and decreasing standard sequences for losses. We used risky prospects instead of riskless money amounts to discourage heuristics like simply computing the difference in absolute values, which we observed in pilot studies where riskless money amounts were used. It is important to emphasize that our results are robust to participants' evaluation of prospects (e.g. according to expected utility or prospect theory) provided that the same theory is used throughout the experiment. As mentioned before, we chose substantial amounts of money to be able to detect utility curvature. A few participants mentioned budgetary constraints in the losses questions. They were told to assume that an interest-free loan was available to pay off the losses.

The starting outcome $\mathrm{x}^{0}$ was $€ 0$ both for gains and for losses. The delay $\mathrm{t}$ was set equal to 1 year in the elicitation of utility. Hence, in the first question we elicited the money amount $\mathrm{x}^{1}$ that made participants indifferent between prospect $G$ at time point 0 and nothing in 1 year and prospect $\mathrm{g}$ at time point 0 and $\mathrm{x}^{1}$ in 1 year. Both for gains and for losses we elicited 6 elements of the standard sequence.

In the second part of the experiment, we elicited the time weights for $t=3$ months, 6 months, 1 year, 2 years, 3 years, and 4 years, both for gains and for losses. The order in which the time weights were elicited was random. Both for gains and for losses, we tested for consistency by repeating the first elicitation at the end of each experimental task. That is, in the elicitation of utility, we repeated the elicitation of $x^{1}$ after $x^{1}, \ldots, x^{6}$ had been elicited and in the 
elicitation of the time weights we repeated the elicitation of the time weight that had been elicited first ${ }^{5}$ after the time weights for 3 months, ..., 4 years had been elicited.

\section{Analyses}

The results for means and medians were similar and, hence, we will only report the medians in the analysis of the aggregate data. Due to the presence of outliers, we focused on nonparametric tests to test for statistical significance.

To investigate the curvature of utility at the individual level, we computed

$$
\partial_{j}=\left(x_{j+1}-x_{j}\right)-\left(x_{j}-x_{j-1}\right), j=1, \ldots, 5,
$$

i.e. how much successive outcome intervals increase or decrease. We observed ten values of $\partial_{\mathrm{j}}$ for each participant, five for gains and five for losses. For gains, a positive value of $\partial_{\mathrm{j}}$ corresponds to a concave part of the utility function. A positive $\partial_{\mathrm{j}}$ means that an individual needs a larger increase in money to obtain a given increase in utility (1/6) at higher amounts than he needs at lower amounts. Likewise, a negative value of $\partial_{\mathrm{j}}$ corresponds to a convex part of the utility function and a value of zero to linear utility. For losses, a positive value of $\partial_{\mathrm{j}}$ corresponds to a convex part of the utility function and a negative value of $\partial_{\mathrm{j}}$ to a concave part.

Both for gains and for losses, we determined for all five $\partial_{\mathrm{j}}$ 's of each participant whether it corresponded to a concave, convex or linear part of the utility function. We classified a participant as having linear (concave, convex) utility if he had at least three linear (concave, convex) parts. Again, we did this both for gains and for losses. We used a criterion of three

\footnotetext{
${ }^{5}$ Recall that the order in which the time weights were elicited was random.
} 
instead of five similar parts, to account for response error. ${ }^{6}$ If none of the three parts (linear, concave or convex) occurred more than twice, the participant was left unclassified.

To smoothen out irregularities in the data, we also analyzed the data under specific parametric assumptions about utility. We examined two parametric families: the power family and the exponential family. Both are widely used in economics and decision analysis. Because the two functions yielded similar results we will only report the results for the power family. Let $\mathrm{z}=\mathrm{x} / \mathrm{x}^{6}, \mathrm{x} \in\left[0, \mathrm{x}^{6}\right]$. The power family is defined by $|\mathrm{z}|^{\mathrm{r}}$ if $\mathrm{r}>0$, by $\ln (\mathrm{z})$ if $\mathrm{r}=0$, and by $-|\mathrm{z}|^{\mathrm{r}}$ if $\mathrm{r}<$ 0. For gains (losses), $r<1$ corresponds to concave (convex) utility and $r>1$ to convex (concave) utility; the case $r=1$ corresponds to linear utility both for gains and for losses. We estimated the parametric families both for the median data and for each individual separately. The estimation was by nonlinear least squares.

We used the estimates of the power coefficients to obtain another, parametric, classification of individual participants. For gains (losses) we classified a participant as concave (convex) if his power coefficient was below 0.95 , as linear if his power coefficient was between 0.95 and 1.05, and as convex (concave) if his power coefficient exceeded 1.05.

To compute the time weights we had to approximate the utility of the elicited outcome $\mathrm{z}$ in (5). We did this by linear approximation. We also used approximation by the estimated power and exponential utility. This affected the results only marginally and we do not report these results separately.

From the elicited time weights we could estimate implied annual discount rates $\rho_{\mathrm{s}}$ as follows:

\footnotetext{
${ }^{6}$ Similar criteria were used by Fennema and van Assen (1999), Abdellaoui (2000), Etchart-Vincent (2004), and
} 


$$
\lambda_{\mathrm{s}}=\frac{1}{\left(1+\rho_{\mathrm{s}}\right)^{\mathrm{s}}}
$$

where $\mathrm{s}$ is time in years. We could then test whether the implied annual discount rates were constant. We computed the difference between the implied annual discount rates for adjacent time periods ${ }^{7}$ and, hence, obtained five observations for each participant both for gains and for losses. If at least three of these observations were positive then the participant was classified as decreasingly impatient, i.e. as having decreasing discount rates over time, if at least three observations were negative then he was classified as increasingly impatient, and if at least three observations were zero then he was classified as a constant discounter. Again, we used a criterion of three out of five to account for response error.

We also used the elicited time weights to estimate the parameter(s) in constant discounting, generalized hyperbolic discounting, proportional discounting, power discounting, and quasi-hyperbolic discounting. Each model was estimated separately, so we did not assume that $\rho$ in constant discounting and $\rho$ in quasi-hyperbolic discounting were equal, that $\gamma$ in generalized hyperbolic discounting and $\gamma$ in proportional discounting were equal or that $\alpha$ in generalized hyperbolic discounting and $\alpha$ in power discounting were equal. The models were estimated by nonlinear least squares both for the median data and for each participant separately. To test whether the results were sensitive to the specification of the unit of time, we performed the estimations for different specifications of the unit of time (years, months, and weeks).

Goodness of fit was assessed by Akaike's information criterion. An important advantage of this criterion is that it takes into account that the discounting models differ in the number of 
parameters employed. The fit of nested models was also compared through likelihood ratio tests. Because the coefficients for the median data were very close to the medians of the estimated coefficients for the individual data, we will focus on the individual data.

\section{Results}

The data of two participants were excluded from the analysis, because these participants gave answers that did not correspond to their reasoning. The data of another participant were lost due to a computer crash. As a result, the data of 67 individuals ( 31 females) were included in the analysis. The consistency of the data was good: none of the tests that we performed revealed significant inconsistencies in participants' responses ( $p>0.05$ in all tests). The individual parametric estimates are given in Appendix D.

\subsection{Gains}

Utility

Concavity of utility was most common at the individual level. Twenty-two participants were classified as concave, 16 as linear, and 7 as convex. The proportion of concave participants was significantly higher than the proportion of convex participants $(\mathrm{p}<0.01)$. The classification based on the individual estimates of the power function also showed predominant concavity: thirty-eight individuals were classified as concave, 12 as linear and 17 as convex. The difference between the proportion of concave and the proportion of convex participants was significant $(\mathrm{p}<$ 0.01). The median of the individual estimates of the coefficient in the power utility function was

\footnotetext{
${ }^{7}$ That is, we computed $\rho_{3 \text { months }}-\rho_{6 \text { months }}, \rho_{6 \text { months }}-\rho_{1 \text { year }}, \rho_{1 \text { year }}-\rho_{\text {2years }}, \rho_{2 \text { years }}-\rho_{3 \text { years }}$, and $\rho_{3 \text { years }}-\rho_{4 \text { years }}$.
} 
0.91 (interquartile range $(\mathrm{IQR})=0.76-1.05)$, which indicated slight concavity. This median was, however, not significantly different from $1(\mathrm{p}=0.075)$.

Figure 1. The Utility Function for Gains Based on the Median Data

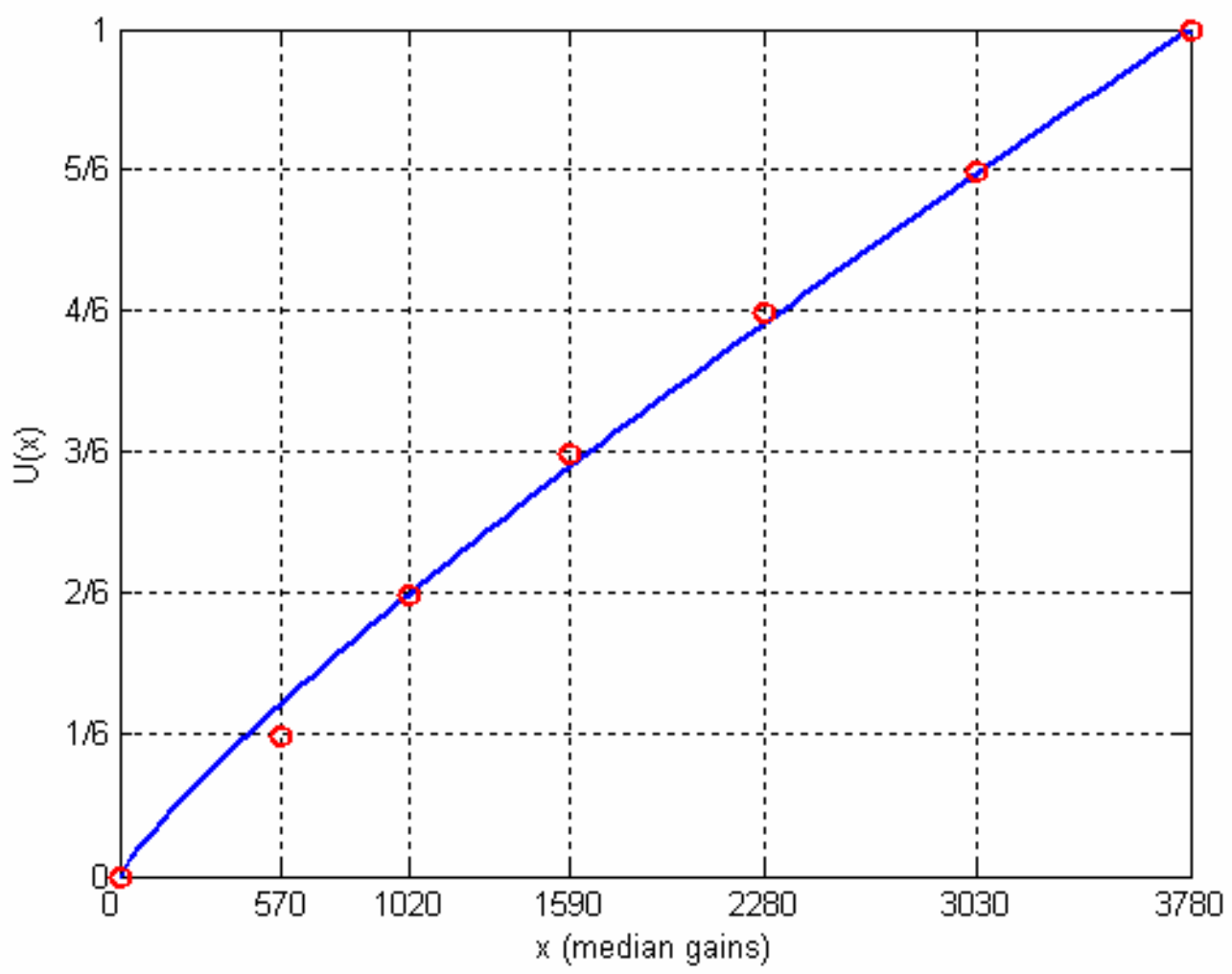

Our findings on utility were comparable to those observed for decision under risk and uncertainty. The proportions of concave and convex participants were slightly lower and the proportion of linear subjects was slightly higher (Abdellaoui 2000, Abdellaoui et al. 2005). The median power coefficient that we observed was similar to studies that estimated the utility for gains in decision under risk and uncertainty. Abdellaoui et al. (2005) and Schunk and Betsch (2006), for example, also found a median estimate of 0.91 for decision under uncertainty, 
whereas for decision under risk this estimate was 0.88 in Tversky and Kahneman (1992) and 0.89 in Abdellaoui (2000).

The aggregate data also showed concavity for gains. Figure 1 displays the utility function for gains based on the median data. The x-axis shows the medians of the elicited elements of the standard sequences for gains, the y-axis their utility. The difference between successive elements

of the standard sequence generally increased, consistent with concave utility. The hypothesis that the difference between successive elements of the standard sequence was constant, the case corresponding to linear utility, could be rejected $(\mathrm{p}<0.01)$. The estimated power coefficient for the median data was 0.84 (White's corrected standard error $=0.027$ ), which differed significantly from $1(\mathrm{p}<0.01)$, the case corresponding to linear utility. Figure 2 also shows the estimated power function. As the figure shows, the fit of the estimation was very good.

\section{Time Weights}

The individual level data showed clear evidence of decreasing impatience: 55 participants were classified as decreasingly impatient and only 12 as increasingly impatient. The difference between the proportion of decreasingly impatient participants and the proportion of increasingly impatient participants was significant $(\mathrm{p}<0.01)$.

Table 1 shows the median time weights for each delay, as well as the median annual discount rates that were implied by these weights. The median implied discount rates were low in comparison with the rates estimated in most previous studies. The median discount rates declined over time, which is consistent with decreasing impatience. The pattern of decreasing impatience was significant: the hypothesis that the implied annual discount rates were constant could be rejected $(\mathrm{p}<0.01)$. 
Table 1. Time Weights and Implied Annual Discount Rates for Gains. Interquartile Ranges in Parentheses.

\begin{tabular}{|c|c|c|c|c|c|c|}
\hline Delay & 3 months & 6 months & 1 year & 2 years & 3 years & 4 years \\
\hline $\begin{array}{l}\text { Median time } \\
\text { weight }\end{array}$ & $\begin{array}{c}0.970 \\
(0.942-0.990)\end{array}$ & $\begin{array}{c}0.944 \\
(0.897-0.978)\end{array}$ & $\begin{array}{c}0.923 \\
(0.787-0.953)\end{array}$ & $\begin{array}{c}0.831 \\
(0.672-0.915)\end{array}$ & $\begin{array}{c}0.735 \\
(0.487-0.891)\end{array}$ & $\begin{array}{c}0.735 \\
(0.352-0.870)\end{array}$ \\
\hline $\begin{array}{l}\text { Annual } \\
\text { discount rate }\end{array}$ & $\begin{array}{c}12.8 \% \\
(4.0 \%-26.9 \%)\end{array}$ & $\begin{array}{c}12.3 \% \\
(4.6 \%-24.3 \%)\end{array}$ & $\begin{array}{c}8.3 \% \\
(4.9 \%-27.1 \%)\end{array}$ & $\begin{array}{c}9.7 \% \\
(4.5 \%-22.0 \%)\end{array}$ & $\begin{array}{c}10.8 \% \\
(3.9 \%-27.1 \%)\end{array}$ & $\begin{array}{c}8.0 \% \\
(3.6 \%-29.9 \%)\end{array}$ \\
\hline
\end{tabular}

Table 2 shows the medians of the estimated individual parameters for each of the five discounting models. Generalized hyperbolic discounting fitted the data best. The difference in goodness of fit between generalized hyperbolic discounting and the other models was always significant. The fit of the other four models was similar and no significant differences were observed. The results were not sensitive to the specification of the unit of time.

Table 2. Medians of the Individual Parameter Estimates for the Discounting Models (Gains)

\begin{tabular}{|l|c|c|c|c|c|c|c|}
\hline \multicolumn{1}{|r|}{ Model } & Constant & Proportional & Power & Generalized Hyperbolic & \multicolumn{2}{|c|}{ Quasi-hyperbolic } \\
\hline Parameter & $\delta^{+}$ & $\gamma^{+}$ & $\alpha^{+}$ & $\gamma^{+}$ & $\alpha^{+}$ & $\beta^{+}$ & $\delta^{+}$ \\
\hline Median & 0.102 & 0.117 & 0.213 & 0.291 & 0.130 & 0.988 & 0.078 \\
$(\mathrm{IQR})$ & $(0.038-0.263)$ & $(0.039-0.309)$ & $(0.080-0.460)$ & $(-0.087-1.952)$ & $(0.070-0.316)$ & $(0.958-1.009)$ & $(0.033-0.208)$ \\
\hline
\end{tabular}

The median value of $\gamma^{+}$in generalized hyperbolic discounting shows limited deviation from constant discounting. The individual estimates of $\gamma^{+}$varied substantially, however. The wide variation of $\gamma^{+}$was caused by poor convergence of the estimation algorithm for some participants. We could reject the hypotheses that $\gamma^{+}$was equal to 0 , the case of constant discounting, or equal to 1 , the case of power discounting, $(\mathrm{p}<0.01$ in both cases) and also the hypothesis that $\alpha^{+}=\gamma^{+}$, the case of proportional discounting $(\mathrm{p}<0.01)$. The parameter $\beta^{+}$in 
quasi-hyperbolic discounting was close to 1 , but significantly lower than $1(\mathrm{p}<0.01)$, suggesting a small but significant immediacy effect. There were only 17 subjects for whom $\beta^{+}$was less than 0.95, which illustrates that for most subjects the immediacy effect was small. Both $\delta^{+}$in constant discounting and $\delta^{+}$in quasi-hyperbolic discounting $(\mathrm{p}=0.02)$ and $\alpha^{+}$in power discounting and $\alpha^{+}$in generalized hyperbolic discounting $(p=0.03)$ differed significantly.

Figure 2: Median Time Weights for Gains and Fit of Parametric Models

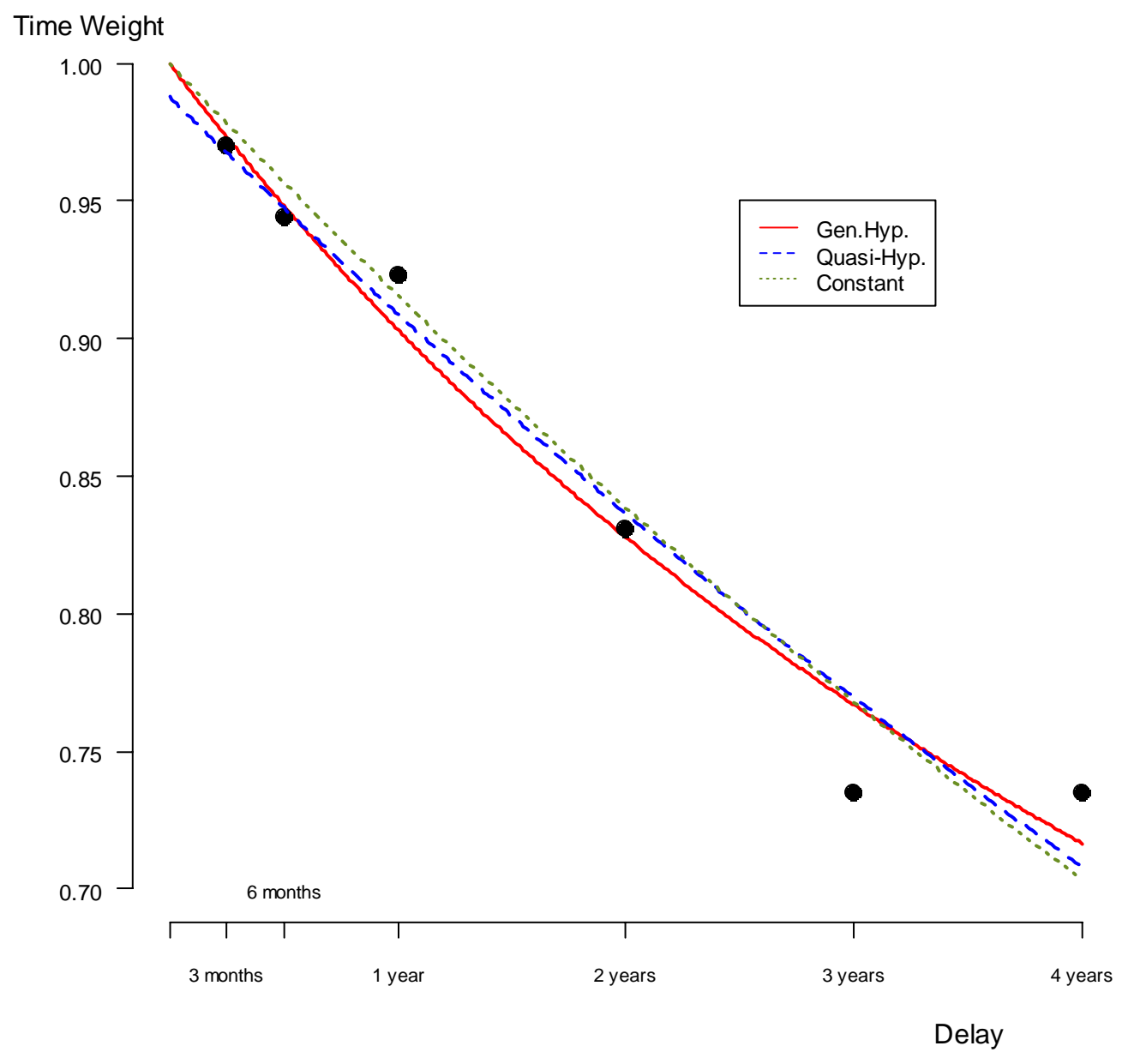


The estimation results based on the median data were largely similar. The main exception was that the immediacy effect was no longer significant. Figure 2 shows the fit of generalized hyperbolic discounting, quasi-hyperbolic discounting and constant discounting to the median data. The results of power discounting and proportional discounting were similar but are not displayed to keep the figure tractable. The figure shows that even though generalized hyperbolic discounting provided the best fit, the differences in fit between the models were limited.

\subsection{Losses}

\section{Utility}

The individual data showed no clear pattern in the direction of concave or convex utility. There were 122 concave parts in total, 98 linear parts, and 125 convex parts. Twenty-two participants had convex utility for losses and 20 had concave utility ( 9 had linear utility, the others could not be classified). The proportion of participants with convex utility did not differ significantly from the proportion with concave utility $(\mathrm{p}>0.10)$. The classification based on the estimates of the power coefficient showed more evidence of convex utility for losses: 30 participants had convex utility, 23 linear utility, and 14 concave utility. The proportion of participants with convex utility was now significantly higher than the proportion with concave utility for losses $(\mathrm{p}=0.01)$. The median of the individual estimates of the coefficient in the power utility function was 0.96 (interquartile range $=0.82-1.04$ ), also indicating slight convexity for losses. This median was not significantly different from $1(\mathrm{p}=0.085)$.

Our findings on utility for losses were also similar to those obtained for decision under risk and under uncertainty. The proportion of convex participants was similar, the proportion of 
concave participants was somewhat higher and the proportion of linear participants somewhat lower (Fennema and van Assen 1999, Abdellaoui 2000, Etchart-Vincent 2004, Abdellaoui et al. 2005). Our median estimate for the power coefficient of 0.96 was close to the estimates of 0.88 in Tversky and Kahneman (1992), 0.84 in Fennema and van Assen (1999), 0.92 in Abdellaoui (2000), and 0.96 for small losses and 0.98 for large losses in Etchart-Vincent (2004).

\section{Figure 3. The Utility Function for Losses Based on the Median Data}

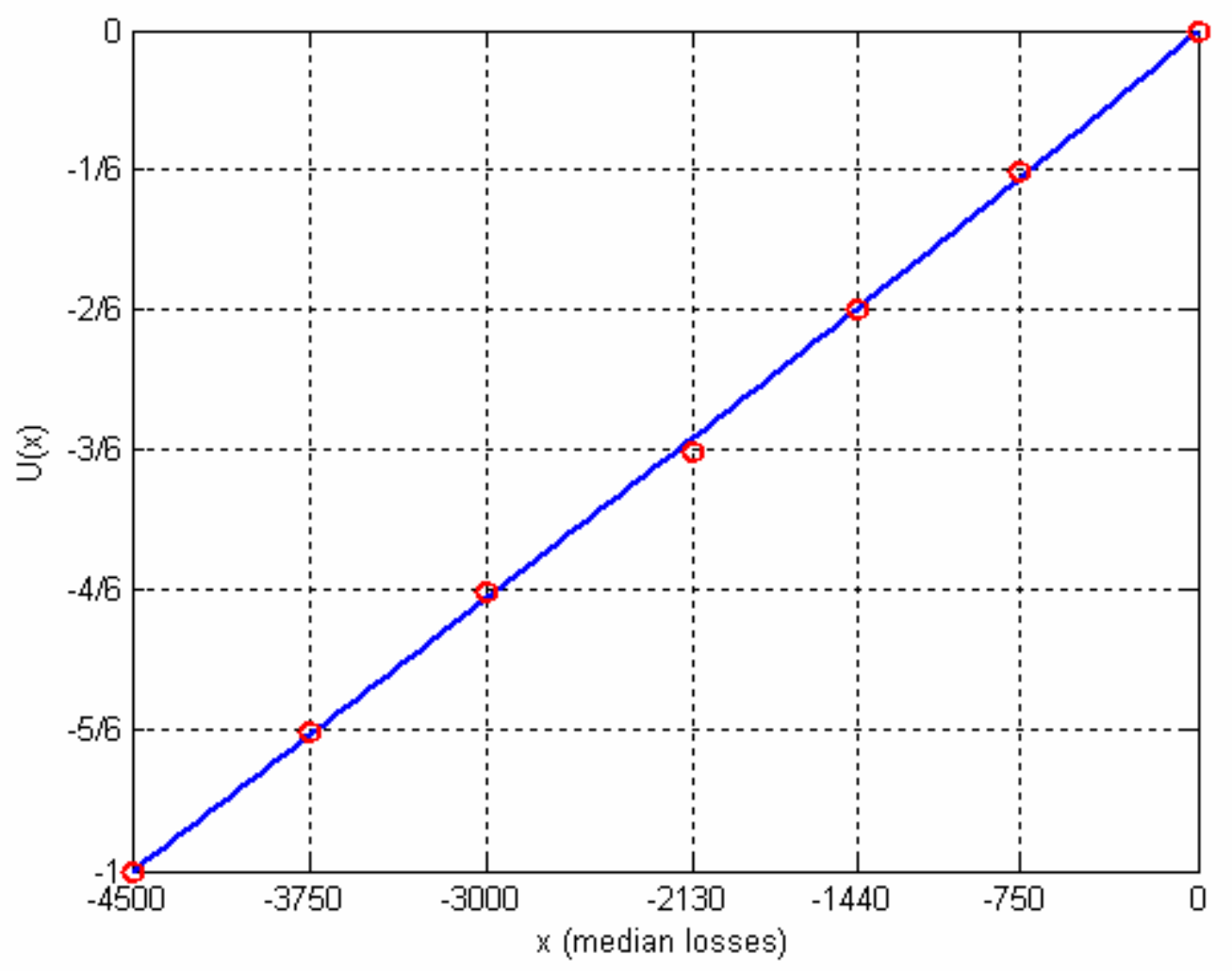

Figure 3 shows the utility for losses based on the median data. The x-axis shows the medians of the elements of the standard sequences. The differences between successive elements of the standard sequence were close and, hence, the utility for losses was close to linear at the aggregate level. We could reject, however, the null hypothesis that the differences between 
successive elements of the standard sequence were all equal $(\mathrm{p}<0.01)$ and, hence, the hypothesis of linear utility.

The estimate of the power coefficient was 0.97 (White's corrected standard error: 0.016), which indicated slight convexity and which was just significantly different from $1(\mathrm{p}=0.05)$. Figure 3 also shows the plot of the estimated power function. The fit of the estimation was very good.

Time Weights

As for gains, decreasing impatience was the most common pattern at the individual level: 47 participants were decreasingly impatient, 18 increasingly impatient, and 2 participants were constant discounters. The proportion of decreasingly impatient participants was significantly higher than the proportion of increasingly impatient participants $(\mathrm{p}<0.01)$.

Table 3 shows the median time weights and the implied annual discount rates for each of the six delays. The discount rates declined over time, as predicted by decreasing impatience, but the decline was modest. The pattern of decreasing impatience was significant, however: the null hypothesis that the implied discount rates were all equal could be rejected $(\mathrm{p}<0.01)$.

Table 3. Time Weights and Implied Annual Discount Rates for Losses. Interquartile Ranges in Parentheses.

\begin{tabular}{|c|c|c|c|c|c|c|}
\hline Delay & 3 months & 6 months & 1 year & 2 years & 3 years & 4 years \\
\hline $\begin{array}{l}\text { Median time } \\
\text { weight }\end{array}$ & $\begin{array}{c}0.984 \\
(0.967-0.991)\end{array}$ & $\begin{array}{c}0.969 \\
(0.928-0.989)\end{array}$ & $\begin{array}{c}0.947 \\
(0.893-0.968)\end{array}$ & $\begin{array}{c}0.898 \\
(0.817-0.941)\end{array}$ & $\begin{array}{c}0.871 \\
(0.752-0.932)\end{array}$ & $\begin{array}{c}0.834 \\
(0.652-0.909)\end{array}$ \\
\hline $\begin{array}{l}\text { Annual } \\
\text { discount rate }\end{array}$ & $\begin{array}{c}6.8 \% \\
(3.8 \%-14.6 \%)\end{array}$ & $\begin{array}{c}6.6 \% \\
(2.3 \%-16.1 \%)\end{array}$ & $\begin{array}{c}5.6 \% \\
(3.3 \%-12.0 \%)\end{array}$ & $\begin{array}{c}5.5 \% \\
(3.1 \%-10.7 \%)\end{array}$ & $\begin{array}{c}4.7 \% \\
(2.4 \%-10.0 \%)\end{array}$ & $\begin{array}{c}4.6 \% \\
(2.4 \%-11.3 \%)\end{array}$ \\
\hline
\end{tabular}


Table 4 shows the estimation results for the five discounting models at the individual level. ${ }^{8}$ As for gains, generalized hyperbolic discounting provided the best fit. It fitted the data significantly better than the other models except that for power discounting the results are ambiguous. Based on Akaike's information criterion generalized hyperbolic discounting did not fit significantly better than power discounting $(p=0.181)$. However, based on the likelihood ratio test we could reject the hypothesis that $\gamma^{-}$was equal to $1(\mathrm{p}<0.01)$.

Proportional discounting fitted significantly worse than all other theories $(\mathrm{p}<0.01$ in all cases). No significant differences in goodness of fit were observed between constant discounting, power discounting, and quasi-hyperbolic discounting. The conclusions about the relative performance of the different theories were not sensitive to the specification of the unit of time.

Table 4. Individual Parameter Estimates for the Discounting Models (losses)

\begin{tabular}{|l|c|c|c|c|c|c|c|}
\hline \multicolumn{1}{|c|}{ Model } & Constant & Proportional & Power & \multicolumn{2}{c|}{ Generalized hyperbolic } & \multicolumn{2}{|c|}{ Quasi-hyperbolic } \\
\hline Parameter & $\rho^{-}$ & $\gamma^{-}$ & $\alpha^{-}$ & $\gamma^{-}$ & $\alpha^{-}$ & $\beta^{-}$ & $\rho^{-}$ \\
\hline Median & 0.056 & 0.090 & 0.120 & 0.512 & 0.100 & 0.989 & 0.046 \\
(IQR) & $(0.032-0.101)$ & $(0.053-0.182)$ & $(0.070-0.208)$ & $(-0.074-1.555)$ & $(0.053-0.242)$ & $(0.969-1.003)$ & $(0.029-0.090)$ \\
\hline
\end{tabular}

The estimate for $\gamma^{-}$in generalized hyperbolic discounting indicated stronger deviations from constant discounting than we observed for gains. The estimates varied substantially across individuals, however. We could reject the hypotheses that $\gamma^{-}$was equal to 0,1 or to $\alpha^{-}$( $p<0.01$ in all cases). The estimate for $\beta^{-}$suggested a small but significant immediacy effect $(\mathrm{p}<0.01)$. Only 15 subjects had a value of $\beta^{-}$smaller than 0.95 , indicating that for most subjects the immediacy effect was modest. The parameters $\rho^{-}$under constant discounting and $\rho^{-}$under quasi-

\footnotetext{
${ }^{8}$ For three participants, it was not possible to estimate the models because they did not discount losses.
} 
hyperbolic discounting differed significantly $(\mathrm{p}<0.01)$; the parameters $\alpha^{-}$under power discounting and $\alpha^{-}$under generalized hyperbolic discounting did not differ significantly $(\mathrm{p}>$ $0.10)$.

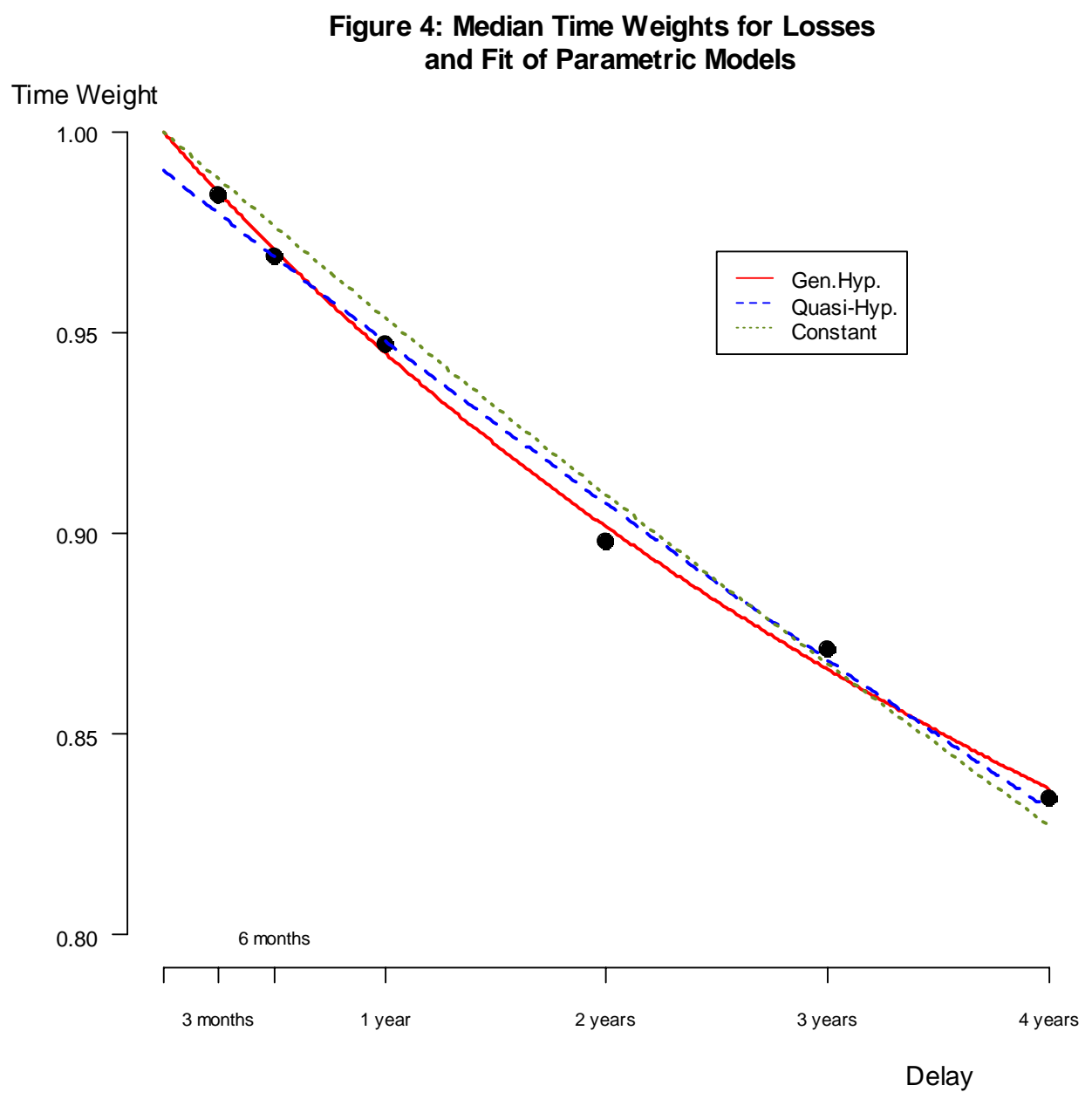

The estimation results based on the median data were largely similar. The main difference was that the immediacy effect was no longer significant and the estimate of $\gamma^{-}$in generalized hyperbolic discounting indicated less deviation from constant discounting and was only 0.228 . This estimate differed significantly from 0 , however $(p=0.027)$. Figure 4 shows the fit to the median data of generalized hyperbolic discounting, quasi-hyperbolic discounting, and constant 
discounting. Generalized hyperbolic fitted the data best, but the figure shows that the fit of quasi-hyperbolic discounting and, to a lesser degree, constant discounting was also good. All parametric models fitted the data better for losses than for gains.

\subsection{Comparison of gains and losses}

In order to check whether there was a gain-loss asymmetry, we investigated the difference between the time weight for gains and the time weight for losses for each delay. As Tables 2 and 4 show, the time weights were higher for losses than for gains. The difference was significant for all delays $(\mathrm{p}=0.02$ for 3 months, $\mathrm{p}<0.01$ for 6 months, $\mathrm{p}=0.03$ for 1 year, $\mathrm{p}<$ 0.01 for 2 years, 3 years, and 4 years).

Mixed results obtained when we compared the parameters in the five discounting models for gains and for losses. Remember that none of the discounting models allows for a difference in these parameters. The estimates in constant discounting and power discounting differed significantly for gains and for losses $(\mathrm{p}<0.01)$. The parameters in generalized hyperbolic discounting and proportional discounting did not differ significantly for gains and for losses $(\mathrm{p}>$ 0.10 in all tests). In the quasi-hyperbolic model, finally, the estimates of $\rho^{+}$and $\rho^{-}$differed significantly $(\mathrm{p}<0.01)$, whereas $\beta^{+}$and $\beta^{-}$did not differ significantly $(\mathrm{p}>0.10)$.

\subsection{The effect on the time weights of assuming linear utility}

As mentioned before, most previous studies that estimated discount rates assumed linear utility. To assess the bias resulting from assuming linear utility, we also computed the time weights under the assumption that utility was linear and compared these with the parameter-free time weights obtained without making assumptions about utility. The median time weights were 
lower under linear utility and, hence, the annual discount rates were higher. However, the time weights under linear utility did not differ significantly from the parameter-free time weights $(p>$ $0.05)$ with the exception of the time weight for 2 years for gains $(p=0.05)$. The gain-loss asymmetry became more pronounced when linear utility was assumed $(p=0.01$ for 3 months, $p$ $=0.02$ for 6 months, $\mathrm{p}<0.01$ for the other delays).

The fit of the discounting models was significantly better when we used the utilityadjusted time weights than when we used the time weights that were computed under the assumption that utility was linear. For gains, the exception was proportional discounting $(p=$ $0.056)$, for losses the exceptions were power discounting $(\mathrm{p}=0.063)$ and generalized hyperbolic discounting $(\mathrm{p}=0.563)$. The conclusions about the relative fit of the discounting models were hardly affected by assuming linear utility. The only differences were that for losses generalized hyperbolic discounting now fitted significantly better than all other models and that proportional discounting no longer fitted significantly worse than constant discounting, quasi-hyperbolic discounting, and power discounting.

\section{Discussion}

Loewenstein and Prelec (1992), extending Kahneman and Tversky (1979) to intertemporal choice, suggested that utility be concave for gains and convex for losses. We found some evidence for their proposition. Our data were consistent with concave utility for gains, but for losses the picture was less clear, although the predominant shape of utility was slightly convex. The power coefficients that we estimated were consistent with Loewenstein and Prelec's (1992) assumption that utility is more elastic for losses than for gains. 
Interestingly, our findings on the degree of utility curvature were close to those obtained in decision under uncertainty and in decision under risk. This held both for gains and for losses. While requiring further evidence, this finding may suggest that there exists one unifying concept of utility. Economists have traditionally argued that utility differs across domains and, hence, that the utility function that is relevant for decision under risk cannot be employed in other contexts, such as intertemporal decision making. In applied economics transferability of utility is, however, commonly assumed. For example, in health economics measurements of utility under risk are routinely used in welfare comparisons. Our findings provide some tentative support for the transferability of utility that is commonly assumed in applied economics.

The discount rates we observed were lower than the rates observed in most previous studies (Frederick et al. 2002). This could not be entirely explained by the fact that, contrary to previous studies, we made no assumptions about utility, because even when linear utility was imposed the observed discount rates were still relatively low. One explanation may be that our experiment was choice-based, whereas most previous studies used matching tasks. It is wellknown that choice tasks tend to produce different results than matching tasks (Tversky et al. 1988). Ahlbrecht and Weber (1997) also observed different discounting patterns in choice than in matching. That said, even though our experimental tasks involved choices, it was clear to participants that we were looking for indifferences and in that sense our task resembled matching (Fischer et al. 1999). Empirical evidence shows that eliciting indifferences through a series of choices, as we did, produces results in between choice and matching (Delquié 1997).

Of the main discounting models that we considered, generalized hyperbolic discounting fitted the data best. The fit of constant discounting was rather good and we could not conclude that quasi-hyperbolic discounting, power discounting or proportional discounting fitted the data 
unambiguously better than constant discounting. One reason why quasi-hyperbolic discounting is used so much in applications is the alleged belief that it fits individual choice behavior better than constant discounting. Our data provide little support for this belief. If the aim of models is to accurately describe individual intertemporal choice behavior then the most appropriate model to use seems generalized hyperbolic discounting. Estimation of the generalized hyperbolic model is no more complicated than quasi-hyperbolic discounting and the fit was significantly better. It should be emphasized, however, that there exist other reasons to use quasi-hyperbolic discounting besides descriptive accuracy, one of which is the greater tractability of the model in theoretical analyses. A cause of concern in our study is the instability of the estimates for the parameter $\gamma$ in generalized hyperbolic discounting.

Our experiment used a neutral frame as did Shelley (1993) and Ahlbrecht and Weber (1997). Contrary to those studies, we observed evidence for a gain-loss asymmetry and, hence, our data do not corroborate the conclusion that the gain-loss asymmetry is caused by a framing effect. The difference between our findings and those of Shelley (1993) and Ahlbrecht and Weber (1997) cannot be explained by the assumption of linear utility made in these studies, because assuming linear utility actually increased the gain-loss asymmetry.

The finding that assuming linear utility seemed not to cause serious biases is important for empirical research into intertemporal preferences. As mentioned before, most studies have hitherto assumed linear utility but it was not known to what extent this assumption distorted their findings. Our results suggest that this distortion was modest. This finding was not caused by our method for measuring utility. An easy heuristic to adopt in responding to the utility elicitation questions might be by keeping the difference between successive elements of the standard sequence constant, which would lead to linear utility. However, both for losses and for gains 
there were only six participants for whom the difference between successive elements of the standard sequence was always constant; there were only three participants for whom the difference between successive elements of the standard sequence was constant both for gains and for losses. These limited numbers suggest that the heuristic may not have caused serious biases.

Our method used chained measurements, i.e. answers from previous questions were used as inputs in later stages. A possible danger of using chained measurements is error propagation: errors in earlier responses get transferred to later responses. Bleichrodt and Pinto (2000) and Abdellaoui et al. (2005) examined the effect of error propagation in their studies and concluded that it had little impact. Since our method was based on a similar chaining process as theirs, their findings suggest that the effect of error propagation was limited in our study as well.

A crucial assumption in our method was that participants behaved according to the general discounting model (1). This model underlies all of the main discounting models used in the literature. A central property of (1) is intertemporal additivity. There is some evidence of violations of intertemporal additivity (Loewenstein and Sicherman 1991, Frank and Hutchens 1993). It is not clear how important these violations of (1) are. As mentioned by Loewenstein and Prelec (1992), they seem particularly relevant when evaluating complete alternative sequences of outcomes like savings plans or multiyear salary contracts. In our experiment, we considered, however, elementary types of intertemporal choices. We tried to mitigate the possible effect of violations of intertemporal additivity by using prospects in the elicitation of utility. We learned from pilot tests that using prospects made it more likely that people viewed things that happened at different points as separate and, hence, behaved more in line with intertemporal additivity. 
The order of the tasks was fixed throughout the experiment. We always started with the gains part, because, as we observed in the pilot sessions, participants found this easier. It may be, although we do not consider this likely, that participants became more aware of their true preferences during the experiment and that this has caused the gain-loss asymmetry in our study. By the construction of our elicitation method, we always had to elicit utility prior to the elicitation of the time weights. We cannot think of any systematic bias that may have arisen because of this.

\section{Conclusion}

This paper has presented a parameter-free method to measure the discounted utility model in its entirety. Hence, we are the first to measure the utility function in intertemporal choice and we provide more robust evidence on the discounting of monetary outcomes. We found concave utility for gains and slightly convex utility for losses, which supports a hypothesis put forward by Loewenstein and Prelec (1992). Utility in intertemporal choice was close to previously found results on utility in decision under risk and uncertainty suggesting the existence of one unifying concept of utility. Our data confirmed decreasing impatience. The decrease was, however, modest and the fit of constant discounting was rather good. Of the hyperbolic discounting models that we examined, generalized hyperbolic discounting fitted the data best. Our data were less supportive of the widely-used quasi hyperbolic discounting model: it did not fit significantly better than constant discounting and the immediacy effect that we observed was small. We found some evidence for a gain-loss asymmetry in the time weights, which contradicts earlier conclusions that the gain-loss asymmetry was due to a framing effect (Shelley 1993, Ahlbrecht and Weber 1997) and also contradicts Loewenstein and Prelec (1992) who suggested that the 
gain-loss asymmetry was a consequence of the shape of the utility function only. Finally, the assumption of linear utility seemed not to bias the estimated time weights and discount rates in a significant manner. Hence, our study suggests that assuming linear utility in future empirical studies and in practical applications may not be very harmful at least for qualitative purposes.

\section{References}

Abdellaoui, M. (2000). Parameter-free elicitation of utilities and probability weighting functions, Management Science, vol. 46, pp. 1497-1512.

Abdellaoui, M., Vossmann, F., and Weber, M. (2005). Choice-based elicitation and decomposition of decision weights for gains and losses under uncertainty, Management Science, vol. 51, pp. 1384-1399.

Ahlbrecht, M. and Weber, M. (1997). An empirical study on intertemporal decision making under risk, Management Science, vol. 43, pp. 813-826.

Ainslie, G. (1975). Specious reward: A behavioral theory of impulsiveness and impuls control, Psychological Bulletin, vol. 82, pp. 463-496.

Andersen, S., Harrison, G. W., Lau, M. I., and Rutström, E. E. (2006). Eliciting risk and time preferences, Working Paper, vol. pp.

Arrow, K. J. (1951). Alternative approaches to the theory of choice in risk-taking situations, Econometrica, vol. 19, pp. 404-437.

Bénabou, R. and Tirole, J. (2002). Self-confidence and personal motivation, Quarterly Journal of Economics, vol. 117, pp. 871-915.

Benzion, U., Rapoport, A., and Yagil, J. (1989). Discount rates inferred from decisions: An experimental study, Management Science, vol. 35, pp. 270-284.

Bernheim, B. D., Skinner, J., and Weinberg, S. (2001). What accounts for the variation in retirement wealth among U.S. Households?, American Economic Review, vol. 91, pp. 832-857.

Bleichrodt, H. and Johannesson, M. (2001). Time preference for health: A test of stationarity versus decreasing timing aversion, Journal of Mathematical Psychology, vol. 45, pp. 265282. 
Bostic, R., Herrnstein, R. J., and Luce, R. D. (1990). The effect on the preference reversal of using choice indifferences, Journal of Economic Behavior and Organization, vol. 13, pp. 193-212.

Brocas, I. and Carrillo, J. D. (2000). The value of information when preferences are dynamically inconsistent, European Economic Review, vol. 44, pp. 1104-1115.

Brocas, I. and Carrillo, J. D. (2001). Rush and discounting under hyperbolic discounting and interdependent activities, Journal of Risk and Uncertainty, vol. 22, pp. 141-164.

Camerer, C. F. and Hogarth, R. M. (1999). The effects of financial incentives in experiments: A review and capital-labor-production framework, Journal of Risk and Uncertainty, vol. 19, pp. 7-42.

Chapman, G. B. (1996). Temporal discounting and utility for health and money, Journal of Experimental Psychology: Learning Memory and Cognition, vol. 22, pp. 771-791.

Delquié, P. (1997). 'Bi-matching': A new preference assessment method to reduce compatibility effects, Management Science, vol. 43, pp. 640-658.

Diamond, P. and Köszegi, B. (2003). Quasi-hyperbolic discounting and retirement, Journal of Public Economics, vol. 87, pp. 1839-1872.

Etchart-Vincent, N. (2004). Is probability weighting sensitive to the magnitude of consequences? An experimental investigation on losses, Journal of Risk and Uncertainty, vol. 28, pp. 217-235.

Fennema, H. and van Assen, M. (1999). Measuring the utility of losses by means of the trade-off method, Journal of Risk and Uncertainty, vol. 17, pp. 277-295.

Fischer, G. W., Carmon, Z., Ariely, D., and Zauberman, G. (1999). Goal-based construction of preferences: Task goals and the prominence effect, Management Science, vol. 45, pp. 1057-1075.

Fishburn, P. C. (1989). Retrospective on the utility theory of von Neumann and Morgenstern, Journal of Risk and Uncertainty, vol. 2, pp. 127-158.

Fishburn, P. C. and Kochenberger, G. A. (1979). Two-piece von Neumann Morgenstern utility functions, Decision Sciences, vol. 10, pp. 503-518.

Frank, R. H. and Hutchens, R. M. (1993). Wages, seniority, and the demand for rising consumption, Journal of Economic Behavior and Organization, vol. 21, pp. 251-276. 
Frederick, S., Loewenstein, G. F., and O'Donoghue, T. (2002). Time discounting and time preference: A critical review, Journal of Economic Literature, vol. 40, pp. 351-401.

Gruber, J. and Köszegi, B. (2001). Is addiction "Rational"? Theory and evidence, Quarterly Journal of Economics, vol. 116, pp. 1261-1303.

Harris, C. and Laibson, D. (2001). Dynamic choices of hyperbolic consumers, Econometrica, vol. 69, pp. 935-957.

Harvey, C. M. (1986). Value functions for infinite period planning, Management Science, vol. 32, pp. 1123-1139.

Herrnstein, R. J. (1981). Self-control as response strength, in: (C. M. Bradshaw, E. Szabadi andC. F. Lowe, eds.), Quantification of steady-state operant behavior, Amsterdam: Elsevier/North Holland.

Hertwig, R. and Ortmann, A. (2001). Experimental practices in economics: A methodological challenge for psychologists?, Behavioral and Brain Sciences, vol. 24, pp. 383-451.

Kahneman, D. and Tversky, A. (1979). Prospect theory: An analysis of decision under risk, Econometrica, vol. 47, pp. 263-291.

Karp, L. (2005). Global warming and hyperbolic discounting, Journal of Public Economics, vol. 89, pp. 261-282.

Kirby, K., N. and Marakovic, N. N. (1995). Modelling myopic decisions: Evidence for hyperbolic delay-discounting within subjects and amounts, Organizational Behavior and Human Decision Processes, vol. 64, pp. 22-30.

Kirby, K. N. (1997). Bidding on the future: Evidence against normative discounting of delayed rewards, Journal of Experimental Psychology: General, vol. 126, pp. 54-70.

Kirby, K. N. and Herrnstein, R. J. (1995). Preference reversals due to myopic discounting of delayed reward, Psychological Science, vol. 6, pp. 83-89.

Krantz, D. H., Luce, R. D., Suppes, P., and Tversky, A. (1971). Foundations of measurement, vol. 1. New York: Academic Press.

Krusell, P. and Smith, A. A. (2003). Consumption-savings decisions with quasi-geometric discounting, Econometrica, vol. 71, pp. 365-375.

Laibson, D. (1997). Golden eggs and hyperbolic discounting, Quarterly Journal of Economics, vol. 112, pp. 443-477. 
Lazaro, A., Barberan, R., and Rubio, E. (2001). Private and social time preferences for health and money: An empirical estimation, Health Economics, vol. 10, pp. 351-356.

Loewenstein, G. F. and Prelec, D. (1992). Anomalies in intertemporal choice: Evidence and an interpretation, Quarterly Journal of Economics, vol. 107, pp. 573-597.

Loewenstein, G. F. and Sicherman, N. (1991). Do workers prefer increasing wage profiles?, Journal of Labor Economics, vol. 9, pp. 67-84.

Luce, R. D. and Raiffa, H. (1957). Games and decisions. New York: Wiley.

O'Donoghue, T. and Rabin, M. (1999). Doing it now or doing it later, American Economic Review, vol. 89, pp. 103-124.

Pennings, J. M. E. and Smidts, A. (2003). The shape of utility functions and organizational behavior, Management Science, vol. 49, pp. 1251-1263.

Phelps, E. S. and Pollak, R. A. (1968). On second-best national savings and game-equilibrium growth, Review of Economic Studies, vol. 35, pp. 185-199.

Read, D. (2001). Is time discounting hyperbolic or subadditive?, Journal of Risk and Uncertainty, vol. 23, pp. 5-32.

Read, D. (2004). Intertemporal choice, in: D. Koehler and N. Harvey (eds.), Blackwell handbook of judgment and decision making, Oxford: Blackwell.

Read, D., Frederick, S., Orsel, B., and Rahman, J. (2005). Four scores and seven years from now: The date/delay effect in temporal discounting, Management Science, vol. 51, pp. 13261335.

Salanié, F. and Treich, N. (2006). Over-savings and hyperbolic discounting, European Economic Review, vol. 50, pp. 1557-1570.

Samuelson, P. A. (1937). A note on the measurement of utility, Review of Economic Studies, vol. 4, pp. 155-161.

Savage, L. J. (1954). The foundations of statistics. New York: Wiley.

Schunk, D. and Betsch, C. (2006). Explaining heterogeneity in utility functions by individual differences in decision modes, Journal of Economic Psychology, vol. 27, pp. 386-401.

Shelley, M. K. (1993). Outcome signs, question frames and discount rates, Management Science, vol. 39, pp. 806-815.

Thaler, R. H. (1981). Some empirical evidence on dynamic inconsistency, Economics Letters, vol. 8, pp. 201-207. 
Tversky, A. and Kahneman, D. (1992). Advances in prospect theory: Cumulative representation of uncertainty, Journal of Risk and Uncertainty, vol. 5, pp. 297-323.

Tversky, A., Sattath, S., and Slovic, P. (1988). Contingent weighting in judgment and choice, Psychological Review, vol. 95, pp. 371-384.

van der Pol, M. M. and Cairns, J. (2002). A comparison of the discounted utility model and hyperbolic discounting models in the case of social and private intertemporal preferences for health, Journal of Economic Behavior and Organization, vol. 49, pp. 79-96.

Wakker, P. P. (1994). Separating marginal utility and probabilistic risk aversion, Theory and Decision, vol. 36, pp. 1-44.

Wakker, P. P. and Deneffe, D. (1996). Eliciting von Neumann-Morgenstern utilities when probabilities are distorted or unknown, Management Science, vol. 42, pp. 1131-1150.

\section{Appendix:}

\section{A. Proof that We Can Freely Choose the Utility of Two Outcomes When the Unit of Time and the Final Period Are the Same Across Temporal Profiles.}

Because the unit of time and the final period are the same across temporal profiles, we restrict comparison to profiles $\mathrm{x}$ and $\mathrm{y}$ where the difference in timing between $\mathrm{x}_{\mathrm{t}-1}$ and $\mathrm{x}_{\mathrm{t}}$ is equal to the difference in timing between $\mathrm{y}_{\mathrm{t}-1}$ and $\mathrm{y}_{\mathrm{t}}$ and also the final periods are the same. Suppose that $\sum_{\mathrm{t}=1}^{\mathrm{T}} \lambda_{\mathrm{t}} \mathrm{u}\left(\mathrm{x}_{\mathrm{t}}\right) \geq \sum_{\mathrm{t}=1}^{\mathrm{T}} \lambda_{\mathrm{t}} \mathrm{u}\left(\mathrm{y}_{\mathrm{t}}\right)$ and that $\sum_{\mathrm{t}=1}^{\mathrm{T}} \lambda_{\mathrm{t}} \mathrm{u}($.$) represents \geqslant$ over temporal profiles. If we replace $\mathrm{u}$ by $\mathrm{v}=\alpha \mathrm{u}+\beta$ with $\alpha>0$ and $\beta$ real, we obtain $\alpha \sum_{\mathrm{t}=1}^{\mathrm{T}} \lambda_{\mathrm{t}} \mathrm{u}\left(\mathrm{x}_{\mathrm{t}}\right)+\beta \sum_{\mathrm{t}=1}^{\mathrm{T}} \lambda_{\mathrm{t}}=\alpha \sum_{\mathrm{t}=1}^{\mathrm{T}} \lambda_{\mathrm{t}} \mathrm{u}\left(\mathrm{x}_{\mathrm{t}}\right)+$ $\beta \sum_{\mathrm{t}=1}^{\mathrm{T}} \lambda_{\mathrm{t}} \geq \alpha \sum_{\mathrm{t}=1}^{\mathrm{T}} \lambda_{\mathrm{t}} \mathrm{u}\left(\mathrm{y}_{\mathrm{t}}\right)+\beta \sum_{\mathrm{t}=1}^{\mathrm{T}} \lambda_{\mathrm{t}}=\sum_{\mathrm{t}=1}^{\mathrm{T}} \lambda_{\mathrm{t}} \mathrm{v}\left(\mathrm{y}_{\mathrm{t}}\right)$. Hence, $\mathrm{v}$ also represents $\succcurlyeq$. Note that the assumption that the unit of time and the final period are the same across the profiles was crucial in the proof. 
B. Example of the Display Participants Faced in the Elicitation of Utility

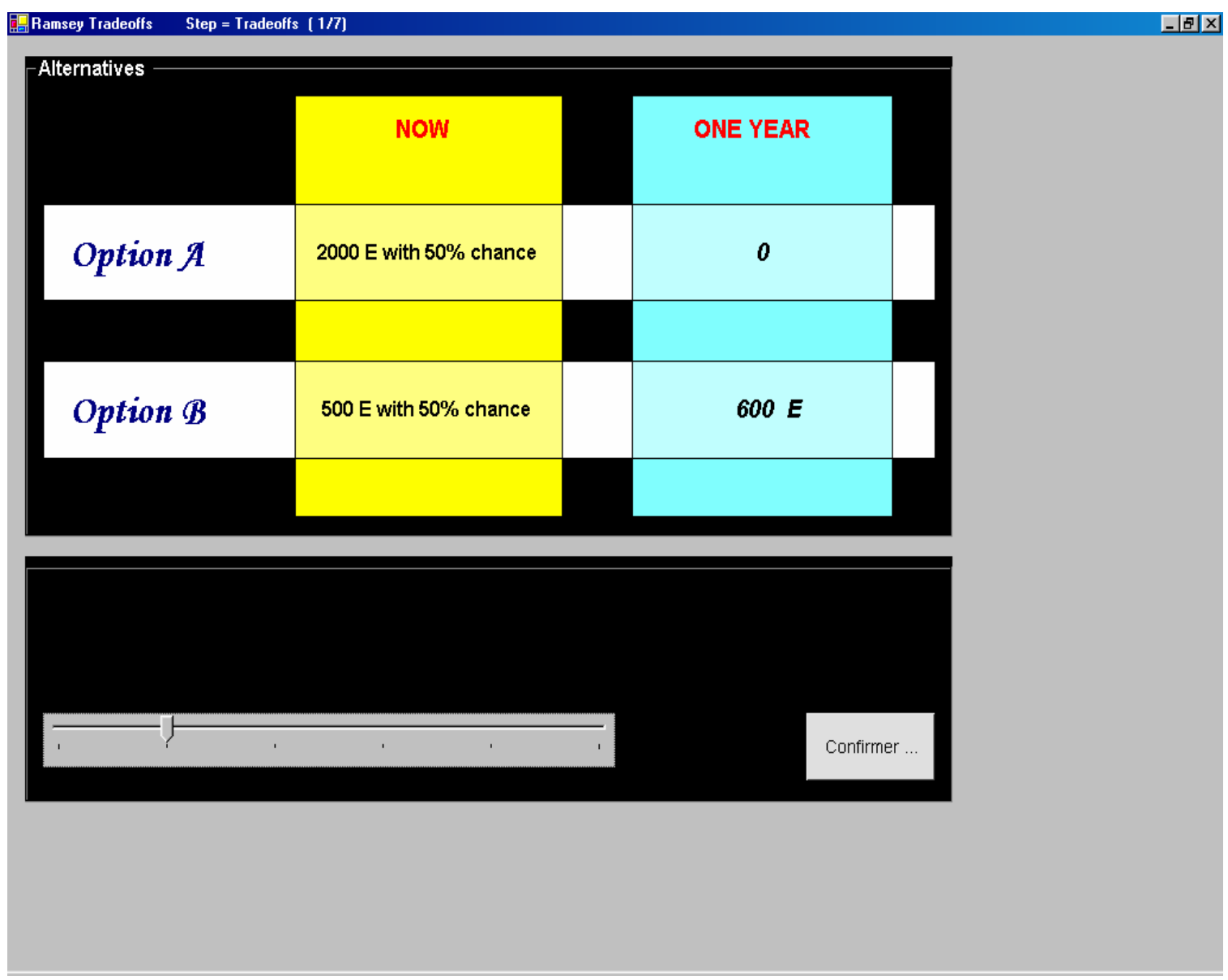


C. Example of the Display Participants Faced in the Elicitation of the Time Weights

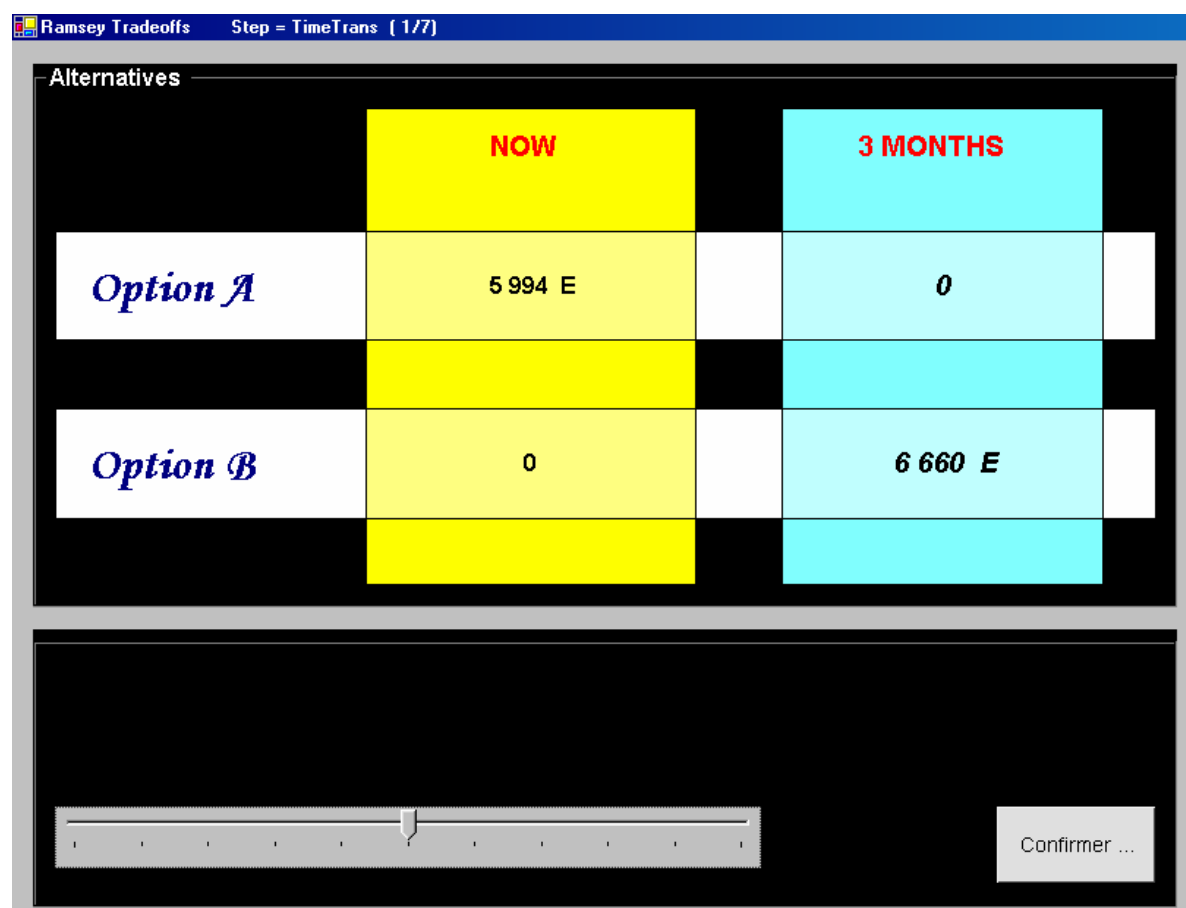




\section{Appendix D: Individual Parameter Estimates}

Table A1. Individual Parameter Estimates for Gains.

\begin{tabular}{|c|c|c|c|c|c|c|c|c|}
\hline Subject & $\begin{array}{c}\rho^{+} \\
(\mathrm{CD})\end{array}$ & $\begin{array}{c}\gamma^{+} \\
(\mathrm{PD})\end{array}$ & $\begin{array}{c}\alpha^{+} \\
\text {(PowD) }\end{array}$ & $\begin{array}{c}\gamma^{+} \\
(\mathrm{GHD})\end{array}$ & $\begin{array}{c}\alpha^{+} \\
(\mathrm{GHD})\end{array}$ & $\begin{array}{c}\rho^{+} \\
(\mathrm{QHD})\end{array}$ & $\begin{array}{c}\beta^{+} \\
(\mathrm{QHD})\end{array}$ & $\begin{array}{c}\mathrm{r}^{+} \\
(\text {PowU) }\end{array}$ \\
\hline 1 & 0.055 & 0.058 & 0.111 & -0.101 & 0.044 & 0.060 & 1.012 & 0.838 \\
\hline 2 & 0.062 & 0.067 & 0.129 & 0.298 & 0.086 & 0.063 & 1.002 & 0.626 \\
\hline 3 & 0.036 & 0.038 & 0.081 & 2.554 & 0.130 & 0.025 & 0.971 & 0.914 \\
\hline 4 & 0.051 & 0.054 & 0.106 & -0.065 & 0.044 & 0.047 & 0.989 & 0.920 \\
\hline 5 & 0.013 & 0.013 & 0.028 & -0.106 & 0.011 & 0.013 & 0.999 & 1.000 \\
\hline 6 & 0.003 & 0.003 & 0.007 & 25.629 & 0.057 & 0.001 & 0.995 & 0.488 \\
\hline 7 & 0.092 & 0.101 & 0.186 & 0.387 & 0.132 & 0.077 & 0.966 & 0.826 \\
\hline 8 & 0.084 & 0.092 & 0.172 & 0.427 & 0.126 & 0.076 & 0.982 & 0.669 \\
\hline 9 & 0.159 & 0.193 & 0.319 & 5.793 & 0.818 & 0.091 & 0.864 & 0.967 \\
\hline 10 & 0.667 & 0.816 & 0.889 & 0.440 & 0.698 & 0.789 & 1.077 & 3.299 \\
\hline 11 & 0.021 & 0.022 & 0.046 & 2.464 & 0.073 & 0.015 & 0.984 & 0.704 \\
\hline 12 & 0.147 & 0.167 & 0.282 & -0.083 & 0.118 & 0.138 & 0.983 & 1.267 \\
\hline 13 & 0.196 & 0.227 & 0.357 & -0.091 & 0.153 & 0.216 & 1.039 & 1.041 \\
\hline 14 & 0.037 & 0.038 & 0.078 & 1.279 & 0.087 & 0.028 & 0.977 & 0.779 \\
\hline 15 & 0.276 & 0.329 & 0.477 & -0.131 & 0.193 & 0.322 & 1.076 & 1.143 \\
\hline 16 & 0.308 & 0.407 & 0.547 & 3.184 & 0.960 & 0.187 & 0.817 & 2.388 \\
\hline 17 & 0.010 & 0.011 & 0.023 & 3.627 & 0.046 & 0.007 & 0.991 & 0.799 \\
\hline 18 & 0.037 & 0.039 & 0.079 & 0.207 & 0.048 & 0.035 & 0.995 & 0.948 \\
\hline 19 & 0.008 & 0.008 & 0.017 & -0.248 & 0.002 & 0.008 & 0.998 & 0.939 \\
\hline 20 & 0.033 & 0.034 & 0.072 & 4.306 & 0.158 & 0.020 & 0.967 & 1.000 \\
\hline 21 & 0.079 & 0.085 & 0.159 & -0.070 & 0.067 & 0.078 & 0.997 & 0.688 \\
\hline 22 & 0.025 & 0.025 & 0.054 & 1.479 & 0.064 & 0.019 & 0.986 & 0.808 \\
\hline 23 & 0.174 & 0.203 & 0.329 & 0.017 & 0.165 & 0.173 & 0.998 & 1.000 \\
\hline 24 & 0.443 & 0.584 & 0.704 & 0.662 & 0.607 & 0.323 & 0.858 & 0.943 \\
\hline 25 & 0.138 & 0.159 & 0.272 & 0.450 & 0.203 & 0.110 & 0.941 & 0.759 \\
\hline 26 & 0.038 & 0.040 & 0.079 & 0.106 & 0.043 & 0.036 & 0.995 & 0.689 \\
\hline 27 & 0.040 & 0.042 & 0.085 & 1.541 & 0.104 & 0.031 & 0.977 & 1.592 \\
\hline 28 & 0.726 & 1.148 & 1.003 & 61.840 & 12.300 & 0.197 & 0.577 & 1.011 \\
\hline 29 & 0.223 & 0.267 & 0.410 & -0.234 & 0.099 & 0.205 & 0.967 & 1.507 \\
\hline 30 & 0.433 & 0.555 & 0.692 & 0.007 & 0.363 & 0.357 & 0.905 & 0.976 \\
\hline 31 & 0.110 & 0.123 & 0.218 & 0.107 & 0.120 & 0.105 & 0.989 & 0.731 \\
\hline 32 & 0.083 & 0.091 & 0.167 & 0.114 & 0.094 & 0.091 & 1.018 & 1.067 \\
\hline 33 & 1.139 & 1.304 & 1.249 & -0.024 & 0.746 & 1.296 & 1.064 & 2.525 \\
\hline 34 & 0.027 & 0.027 & 0.058 & 2.959 & 0.100 & 0.018 & 0.978 & 0.883 \\
\hline 35 & 0.250 & 0.292 & 0.437 & -0.181 & 0.153 & 0.291 & 1.072 & 1.000 \\
\hline 36 & 1295.3 & 20.525 & 7.697 & 50.388 & 36.460 & 2.077 & 0.201 & 3.277 \\
\hline 37 & 0.324 & 0.368 & 0.530 & -0.233 & 0.164 & 0.434 & 1.180 & 1.112 \\
\hline 38 & 1.472 & 1.503 & 1.324 & 1.074 & 1.354 & 1.225 & 0.939 & 5.905 \\
\hline 39 & 0.203 & 0.230 & 0.368 & -0.247 & 0.075 & 0.197 & 0.988 & 0.820 \\
\hline 40 & 0.376 & 0.440 & 0.595 & -0.114 & 0.270 & 0.515 & 1.181 & 0.885 \\
\hline 41 & 0.028 & 0.029 & 0.066 & 95160.1 & 602.89 & 0.001 & 0.931 & 0.786 \\
\hline 42 & 0.112 & 0.129 & 0.229 & 1.243 & 0.252 & 0.088 & 0.946 & 1.075 \\
\hline 43 & 0.578 & 0.761 & 0.843 & 0.583 & 0.703 & 0.458 & 0.890 & 0.730 \\
\hline 44 & 0.151 & 0.174 & 0.289 & 0.057 & 0.152 & 0.162 & 1.022 & 1.451 \\
\hline 45 & 0.102 & 0.117 & 0.213 & 3.515 & 0.407 & 0.066 & 0.918 & 1.018 \\
\hline 46 & 0.125 & 0.138 & 0.238 & -0.178 & 0.079 & 0.143 & 1.040 & 0.772 \\
\hline 47 & 0.010 & 0.010 & 0.022 & 0.119 & 0.012 & 0.009 & 0.996 & 0.755 \\
\hline 48 & 0.029 & 0.029 & 0.059 & -0.031 & 0.027 & 0.032 & 1.008 & 0.694 \\
\hline
\end{tabular}




$\begin{array}{llllrllll}49 & 0.040 & 0.042 & 0.085 & 0.561 & 0.068 & 0.034 & 0.984 & 0.824 \\ 50 & 0.167 & 0.194 & 0.315 & 0.044 & 0.165 & 0.172 & 1.010 & 0.780 \\ 51 & 0.357 & 0.418 & 0.578 & -0.215 & 0.194 & 0.456 & 1.144 & 1.054 \\ 52 & 0.027 & 0.028 & 0.059 & 3.778 & 0.118 & 0.018 & 0.975 & 0.668 \\ 53 & 0.193 & 0.252 & 0.388 & 17.477 & 2.097 & 0.074 & 0.784 & 1.045 \\ 54 & 0.586 & 0.729 & 0.839 & 0.038 & 0.481 & 0.604 & 1.016 & 2.065 \\ 55 & 0.033 & 0.034 & 0.067 & -0.140 & 0.024 & 0.035 & 1.005 & 1.000 \\ 56 & 0.049 & 0.052 & 0.104 & 0.551 & 0.083 & 0.040 & 0.976 & 0.594 \\ 57 & 0.041 & 0.042 & 0.081 & -0.222 & 0.020 & 0.048 & 1.019 & 0.755 \\ 58 & 0.054 & 0.057 & 0.112 & 0.070 & 0.058 & 0.051 & 0.993 & 1.000 \\ 59 & 0.069 & 0.076 & 0.151 & 27.768 & 1.200 & 0.027 & 0.900 & 0.641 \\ 60 & 0.404 & 0.554 & 0.672 & 1.610 & 0.824 & 0.285 & 0.852 & 1.151 \\ 61 & 0.327 & 0.377 & 0.541 & -0.247 & 0.141 & 0.413 & 1.141 & 0.729 \\ 62 & 0.165 & 0.192 & 0.315 & -0.145 & 0.114 & 0.157 & 0.982 & 0.855 \\ 63 & 0.194 & 0.226 & 0.358 & -0.098 & 0.149 & 0.205 & 1.021 & 2.969 \\ 64 & 0.076 & 0.083 & 0.156 & 0.292 & 0.103 & 0.070 & 0.986 & 0.732 \\ 65 & 0.072 & 0.079 & 0.154 & 2.294 & 0.231 & 0.050 & 0.948 & 0.774 \\ 66 & 0.030 & 0.031 & 0.064 & 0.548 & 0.051 & 0.026 & 0.991 & 0.845 \\ 67 & 0.331 & 0.447 & 0.576 & 2.375 & 0.859 & 0.211 & 0.833 & 0.736\end{array}$

Note: $\mathrm{CD}=$ constant discounting, PowD = power discounting, $\mathrm{GHD}=$ generalized hyperbolic discounting, $\mathrm{QHD}=$ quasi-hyperbolic discounting, $\mathrm{PD}=$ proportional discounting, $\mathrm{Pow} \mathrm{U}=$ power utility

Table A2: Individual Parameter Estimates for Losses

\begin{tabular}{rrrrrrrrr} 
Subject & \multicolumn{1}{c}{$\begin{array}{c}\rho^{-} \\
(\mathrm{CD})\end{array}$} & \multicolumn{1}{c}{$\gamma^{-}$} & \multicolumn{1}{c}{$\alpha^{-}$} & \multicolumn{1}{c}{$\gamma^{-}$} & \multicolumn{1}{c}{$\alpha^{-}$} & \multicolumn{1}{c}{$\rho^{-}$} & \multicolumn{1}{c}{$\beta^{-}$} & \multicolumn{1}{c}{$\mathrm{r}^{-}$} \\
1 & 0.072 & 0.115 & 0.153 & 2.102 & 0.219 & 0.052 & 0.950 & 1.027 \\
2 & 0.026 & 0.038 & 0.059 & 3.331 & 0.110 & 0.018 & 0.976 & 0.732 \\
3 & 0.018 & 0.027 & 0.038 & -0.042 & 0.017 & 0.018 & 1.001 & 0.896 \\
4 & 0.017 & 0.025 & 0.035 & -0.230 & 0.008 & 0.017 & 0.999 & 0.799 \\
5 & 0.017 & 0.025 & 0.037 & 0.730 & 0.033 & 0.015 & 0.993 & 0.911 \\
6 & & & & & & & & 0.792 \\
7 & 0.084 & 0.138 & 0.173 & 0.367 & 0.121 & 0.074 & 0.974 & 0.971 \\
8 & 0.009 & 0.014 & 0.021 & 2.329 & 0.032 & 0.007 & 0.993 & 0.810 \\
9 & 0.045 & 0.069 & 0.094 & 0.263 & 0.060 & 0.040 & 0.989 & 0.634 \\
10 & 0.061 & 0.093 & 0.135 & 3.694 & 0.267 & 0.037 & 0.943 & 1.157 \\
11 & 0.014 & 0.020 & 0.033 & 25.542 & 0.247 & 0.006 & 0.978 & 0.897 \\
12 & 0.100 & 0.168 & 0.197 & -0.191 & 0.059 & 0.101 & 1.002 & 1.088 \\
13 & 0.255 & 0.533 & 0.465 & 1.034 & 0.472 & 0.209 & 0.925 & 0.734 \\
14 & 0.032 & 0.048 & 0.070 & 2.200 & 0.103 & 0.024 & 0.978 & 0.782 \\
15 & & & & & & & & 0.914 \\
16 & 0.541 & 1.158 & 0.803 & 1.547 & 0.960 & 0.332 & 0.799 & 5.151 \\
17 & 0.134 & 0.228 & 0.262 & 28.930 & 2.063 & 0.086 & 0.892 & 1.200 \\
18 & 0.046 & 0.071 & 0.095 & 0.115 & 0.053 & 0.047 & 1.003 & 1.010 \\
19 & 0.069 & 0.109 & 0.143 & 0.512 & 0.111 & 0.065 & 0.990 & 0.977 \\
20 & 0.132 & 0.234 & 0.257 & -0.002 & 0.124 & 0.128 & 0.990 & 1.415 \\
21 & 0.089 & 0.145 & 0.184 & 1.208 & 0.200 & 0.067 & 0.949 & 1.023 \\
22 & 0.037 & 0.056 & 0.079 & 0.751 & 0.070 & 0.031 & 0.985 & 0.805 \\
23 & 0.132 & 0.231 & 0.252 & -0.179 & 0.082 & 0.145 & 1.029 & 1.000 \\
24 & 0.341 & 0.785 & 0.589 & 1.080 & 0.608 & 0.269 & 0.900 & 0.901 \\
25 & 829.49 & 20.916 & 7.303 & 1162.94 & 382.88 & 0.330 & 0.150 & 1.759
\end{tabular}




\begin{tabular}{|c|c|c|c|c|c|c|c|c|}
\hline 26 & 0.037 & 0.057 & 0.076 & -0.066 & 0.032 & 0.040 & 1.007 & 1.008 \\
\hline 27 & 0.042 & 0.064 & 0.086 & -0.046 & 0.038 & 0.042 & 1.002 & 1.285 \\
\hline 28 & 0.371 & 0.794 & 0.610 & -0.104 & 0.267 & 0.377 & 1.009 & 1.252 \\
\hline 29 & 0.055 & 0.084 & 0.120 & 8.358 & 0.401 & 0.030 & 0.939 & 1.027 \\
\hline 30 & 0.424 & 0.974 & 0.689 & 0.958 & 0.678 & 0.321 & 0.876 & 1.000 \\
\hline 31 & 0.018 & 0.026 & 0.040 & 1.051 & 0.040 & 0.015 & 0.992 & 0.964 \\
\hline 32 & 1.100 & 2.339 & 1.209 & 1.004 & 1.211 & 0.690 & 0.810 & 2.393 \\
\hline 33 & 0.072 & 0.117 & 0.145 & -0.074 & 0.061 & 0.075 & 1.006 & 1.355 \\
\hline 34 & 0.085 & 0.139 & 0.173 & 0.306 & 0.116 & 0.085 & 0.999 & 1.047 \\
\hline 35 & 0.061 & 0.098 & 0.126 & 0.070 & 0.066 & 0.064 & 1.005 & 1.000 \\
\hline 36 & 0.015 & 0.020 & 0.034 & 6.819 & 0.100 & 0.008 & 0.981 & 0.735 \\
\hline 37 & 0.068 & 0.106 & 0.139 & 0.256 & 0.089 & 0.070 & 1.005 & 0.586 \\
\hline 38 & 0.037 & 0.056 & 0.076 & -0.158 & 0.025 & 0.038 & 1.003 & 0.543 \\
\hline 39 & 0.049 & 0.075 & 0.108 & 2.531 & 0.171 & 0.035 & 0.963 & 1.045 \\
\hline 40 & 0.165 & 0.299 & 0.297 & -0.233 & 0.078 & 0.223 & 1.123 & 0.653 \\
\hline 41 & 0.013 & 0.019 & 0.028 & -0.216 & 0.007 & 0.008 & 0.987 & 1.160 \\
\hline 42 & 0.036 & 0.056 & 0.073 & -0.174 & 0.023 & 0.038 & 1.006 & 0.930 \\
\hline 43 & 0.038 & 0.059 & 0.077 & -0.209 & 0.021 & 0.043 & 1.013 & 1.075 \\
\hline 44 & & & & & & & & 0.987 \\
\hline 45 & 0.098 & 0.162 & 0.208 & 6.844 & 0.601 & 0.053 & 0.899 & 1.007 \\
\hline 46 & 0.041 & 0.061 & 0.087 & 0.690 & 0.075 & 0.034 & 0.984 & 0.765 \\
\hline 47 & 0.014 & 0.021 & 0.031 & 0.988 & 0.031 & 0.012 & 0.993 & 0.715 \\
\hline 48 & 0.022 & 0.031 & 0.047 & 1.526 & 0.057 & 0.016 & 0.984 & 0.901 \\
\hline 49 & 0.056 & 0.089 & 0.116 & 0.146 & 0.066 & 0.055 & 0.996 & 0.847 \\
\hline 50 & 0.168 & 0.311 & 0.317 & 0.063 & 0.169 & 0.173 & 1.010 & 1.047 \\
\hline 51 & 0.358 & 0.753 & 0.586 & -0.132 & 0.246 & 0.411 & 1.074 & 0.952 \\
\hline 52 & 0.052 & 0.080 & 0.112 & 1.317 & 0.126 & 0.041 & 0.971 & 0.893 \\
\hline 53 & 0.101 & 0.170 & 0.208 & 1.483 & 0.249 & 0.077 & 0.945 & 0.780 \\
\hline 54 & 0.203 & 0.380 & 0.373 & -0.235 & 0.089 & 0.204 & 1.002 & 1.000 \\
\hline 55 & 0.048 & 0.074 & 0.099 & -0.022 & 0.045 & 0.044 & 0.991 & 1.000 \\
\hline 56 & 0.073 & 0.120 & 0.146 & -0.241 & 0.029 & 0.077 & 1.008 & 0.962 \\
\hline 57 & 0.022 & 0.032 & 0.046 & -0.102 & 0.017 & 0.018 & 0.990 & 0.961 \\
\hline 58 & 0.059 & 0.093 & 0.120 & -0.048 & 0.052 & 0.060 & 1.003 & 1.000 \\
\hline 59 & 0.211 & 0.403 & 0.391 & -0.099 & 0.160 & 0.180 & 0.942 & 1.276 \\
\hline 60 & 0.083 & 0.134 & 0.168 & 0.142 & 0.096 & 0.073 & 0.978 & 1.633 \\
\hline 61 & 0.272 & 0.521 & 0.459 & -0.245 & 0.118 & 0.364 & 1.165 & 0.669 \\
\hline 62 & 0.059 & 0.091 & 0.128 & 3.398 & 0.242 & 0.039 & 0.950 & 0.876 \\
\hline 63 & 0.027 & 0.039 & 0.060 & 4.674 & 0.139 & 0.016 & 0.972 & 0.654 \\
\hline 64 & 0.041 & 0.063 & 0.087 & 0.599 & 0.071 & 0.034 & 0.983 & 0.937 \\
\hline 65 & 0.014 & 0.020 & 0.032 & 54.506 & 0.431 & 0.006 & 0.977 & 0.822 \\
\hline 66 & 0.022 & 0.033 & 0.047 & -0.090 & 0.019 & 0.022 & 1.000 & 0.986 \\
\hline 67 & 0.043 & 0.064 & 0.092 & 1.555 & 0.113 & 0.033 & 0.974 & 0.938 \\
\hline
\end{tabular}

Note: $\mathrm{CD}=$ constant discounting, PowD = power discounting, $\mathrm{GHD}=$ generalized hyperbolic discounting, $\mathrm{QHD}=$ quasi-hyperbolic discounting, $\mathrm{PD}=$ proportional discounting, $\mathrm{Pow} \mathrm{U}=$ power utility 